\title{
The Effect of the Ocean Eddy on Tropical Cyclone Intensity
}

\author{
Chun-Chieh Wu, Chia-Ying Lee, And I.-I Lin \\ Department of Atmospheric Sciences, National Taiwan University, Taipei, Taiwan
}

(Manuscript received 17 March 2006, in final form 12 February 2007)

\begin{abstract}
The rapid intensification of Hurricane Katrina followed by the devastation of the U.S. Gulf States highlights the critical role played by an upper-oceanic thermal structure (such as the ocean eddy or Loop Current) in affecting the development of tropical cyclones. In this paper, the impact of the ocean eddy on tropical cyclone intensity is investigated using a simple hurricane-ocean coupled model. Numerical experiments with different oceanic thermal structures are designed to elucidate the responses of tropical cyclones to the ocean eddy and the effects of tropical cyclones on the ocean. This simple model shows that rapid intensification occurs as a storm encounters the ocean eddy because of enhanced heat flux. While strong winds usually cause strong mixing in the mixed layer and thus cool down the sea surface, negative feedback to the storm intensity of this kind is limited by the presence of a warm ocean eddy, which provides an insulating effect against the storm-induced mixing and cooling.

Two eddy factors, $F_{\text {EDDY-S }}$ and $F_{\text {EDDY-T }}$, are defined to evaluate the effect of the eddy on tropical cyclone intensity. The efficiency of the eddy feedback effect depends on both the oceanic structure and other environmental parameters, including properties of the tropical cyclone. Analysis of the functionality of $F_{\text {EDDY-T }}$ shows that the mixed layer depth associated with either the large-scale ocean or the eddy is the most important factor in determining the magnitude of eddy feedback effects. Next to them are the storm's translation speed and the ambient relative humidity.
\end{abstract}

\section{Introduction}

It has been widely recognized that the ocean supplies surface heat fluxes-and therefore energy-to tropical cyclones (TCs). The TC can induce the sea surface temperature (SST) cooling (Price 1981) associated with both the entrainment/mixing and upwelling processes. In turn, the SST cooling near the storm core exerts influence on the TC intensity. This negative feedback to the TC intensity is clearly a function of the oceanic thermal conditions (Bender et al. 1993; Schade and Emanuel 1999; Hong et al. 2000; Shay et al. 2000; Bender and Ginis 2000; Chan et al. 2001; Lin et al. 2005). In particular, the role of warm ocean eddies or rings in the previously mentioned typhoon-ocean interaction has been underscored (Hong et al. 2000; Shay et al. 2000; Goni and Trinanes 2003; Kaplan and DeMaria 2003; Emanuel et al. 2004; Lin et al. 2005). Studies of Hurricanes Opal (1995), Mitch (1998), and Bret (1999)

Corresponding author address: Chun-Chieh Wu, Department of Atmospheric Sciences, National Taiwan University, No. 1, Sec. 4, Roosevelt Rd., Taipei 106, Taiwan.

E-mail: cwu@typhoon.as.ntu.edu.tw in the Atlantic and of Supertyphoon Maemi (2003) in the northwestern Pacific have consistently seen rapid TC intensification when the storms moved across warm ocean eddies (Shay et al. 2000; Goni and Trinanes 2003; Lin et al. 2005). Hurricane Katrina (2005), which devastated the Gulf States, is yet another case in point that intensified from category 1 to category 5 within two days while passing the warm Loop Current over the Gulf of Mexico (Scharroo et al. 2005).

Recently Lin et al. (2005) have integrated the satellite altimetry data into a very simple coupled model to show that the presence of the warm ocean eddy can serve as an efficient insulator against the ocean's negative feedback, helping maintain and even boost the TC intensity. Note that the coupled model used by Lin et al. (2005) is a rather simplified atmospheric model (Emanuel 1999) coupled with a one-dimensional ocean model (Schade 1997). To elaborate the findings of Lin et al. (2005), we adopt a slightly more sophisticated coupled model, though still simple enough (Emanuel 1989; Schade and Emanuel 1999; Korty 2002), to systematically evaluate the role of the oceanic thermal structure in TC intensity evolution. In particular, we wish to quantify the influence of the ocean eddy on TC 
intensity and to provide a new perspective on the physics therein. The model and experiment design is presented in section 2. Results are detailed in section 3 , followed by the conclusion and future work in the final section.

\section{Model description and experiment design}

\section{a. Model description}

The hurricane-ocean coupled model used in this study was constructed from two independently developed and tested models, namely, the axisymmetric hurricane model by Emanuel (1989) and the four-layer ocean model by Cooper and Thompson (1989).

The axisymmetric hurricane model in gradient wind and hydrostatic balance consists of three vertical layers. In the horizontal sense, it uses the potential radius coordinate [ $R$ surface; see Eq. (1)], which permits higher resolution within the eyewall at low computational cost. Potential radius $(R)$ is proportional to the square root of the absolute angular momentum per unit mass around the storm center and is defined as

$$
f R^{2}=2 r V+f r^{2},
$$

where $r$ is the physical radius, $V$ the azimuthal velocity, and $f$ the Coriolis parameter.

In cylindrical coordinates, the hydrostatic form of the mass continuity equation is

$$
\frac{1}{r} \frac{\partial(r u)}{\partial r}+\frac{\partial \omega}{\partial p}=0
$$

where $u$ is the horizontal velocity and $\omega$ is the vertical pressure velocity.

The temperature variable in this model is saturation moist entropy $\left(s^{*}\right)$. This is the moist entropy the atmosphere would have if it were saturated while holding both temperature and pressure constant. This variable (neglecting effects of water substance on heat capacities, and so forth) is approximately

$$
s^{*}=c_{p} \ln T+\frac{L_{v} r^{*}}{T}-R_{d} \ln \frac{p}{p_{a}},
$$

where $T$ is the temperature, $L_{v}$ the latent heat of vaporization, $r^{*}$ the saturation mixing ratio, $R_{d}$ the gas constant of dry air, and $p_{a}$ a reference pressure value chosen to be the ambient (unperturbed) sea level pressure far from the storm.

Here $s_{s}^{*}$ is the saturation moist entropy at SST and surface pressure, and the aerodynamic flux formula has been used in the surface heat flux term, which is the most important energy source to TC genesis and devel- opment. Thus $s_{s}^{*}$ can be expressed as a difference from the ambient subcloud layer moist entropy, $S_{B a}$; that is,

$$
\begin{aligned}
s_{s}^{*}= & s_{B a}+c_{p} \ln \left(\frac{T_{s}}{T_{s_{a}}}\right)-R_{d} \ln \left(\frac{p_{s}}{p_{a}}\right) \\
& +\frac{L_{v} r^{*}\left(T_{s_{a}}, p_{a}\right)}{T_{s_{a}}}\left[\frac{T_{s_{a}} p_{a}-e^{*}\left(T_{s_{a}}\right)}{T_{s}} \frac{e^{*}\left(T_{s}\right)}{p_{s}-e^{*}\left(T_{s}\right)}-H_{a}\right],
\end{aligned}
$$

where subscripts " $s$ " and " $a$ " refer to the surface and ambient (unperturbed) values, respectively. Here $e^{*}$ is the saturation vapor pressure and $H_{a}$ is the relative humidity in the ambient environment.

The ocean model includes four active layers: a thin well-mixed layer on top of two strongly stratified layers and a deep abyssal layer. For layer $i$, the momentum equation is written as

$$
\begin{aligned}
\frac{\partial \mathbf{V}_{i}}{\partial t}= & -f \mathbf{K} \times \mathbf{V}_{i}-\left(\boldsymbol{\nabla} \cdot \mathbf{V}_{i}+\mathbf{V}_{i} \cdot \boldsymbol{\nabla}\right) \mathbf{v}_{i}-h_{i} \mathbf{P}_{i} \\
& +\frac{\boldsymbol{\tau}_{s} \delta_{1 i}}{\rho_{\mathrm{H}_{2} \mathrm{O}}}+\mathbf{W}_{v_{i}},
\end{aligned}
$$

where

$$
\mathbf{V}_{i}=\mathbf{v}_{i} h_{i}
$$

is the horizontal flow vector, $\mathbf{v}_{i}$ is the horizontal velocity, $h_{i}$ is the layer depth, $f$ is the Coriolis parameter, $\mathbf{K}$ is the unit vector pointing upward, $\mathbf{P}_{i}$ is the pressure gradient force, $\boldsymbol{\tau}_{s}$ is the surface wind stress, $\delta_{1 i}$ is defined as

$$
\delta_{1 i}=\left\{\begin{array}{ll}
1 & \text { for } i=1 \\
0 & \text { otherwise }
\end{array},\right.
$$

$\rho_{\mathrm{H}_{2} \mathrm{O}}$ is a reference density of water, and $\mathbf{W}_{v_{i}}$ represents the entrainment effect of fluid from one layer into another. The subscript $i$ always refers to the layer $i$ and bold capitals indicate vector quantities. The right-hand terms of Eq. (5) are the Coriolis term, divergence (pumping) term, advection term, pressure gradient term, surface stress, and entrainment term in sequence. The entrainment term in Eq. (5) describes the effect on the momentum budget of turbulent entrainment from the upper thermocline into the mixed layer:

$$
\mathbf{W}_{v_{i}}= \begin{cases}\mathbf{v}_{2} \omega_{e} & \text { for } i=1 \\ -\mathbf{v}_{2} \omega_{e} & \text { for } i=2 \\ 0 & \text { otherwise }\end{cases}
$$

where $\omega_{e}$ is the so-called entrainment velocity at which the layer interface would move under the isolated effect of entrainment. In this model, the entrainment velocity 
is parameterized by the Richardson number (Pollard et al. 1973; Price 1981):

$$
\omega_{e}=\left\{\begin{array}{ll}
5 \times 10^{-4} R_{v}^{-4} \delta v & \text { if } 0 \leq R_{v} \leq 1 \\
0 & \text { otherwise }
\end{array},\right.
$$

where $R_{v}$ is the bulk Richardson number based on the depth of the mixed layer, $h_{1}$, and the density and the velocity jump, $\delta \rho$ and $\delta v$, across the base of the mixed layer:

$$
R_{v}=g \frac{\delta \rho}{\rho_{\mathrm{H}_{2} \mathrm{O}}} \frac{h_{1}}{(\delta v)^{2}} .
$$

For each layer depth, mass continuity yields as

$$
\frac{\partial h_{i}}{\partial t}=-\boldsymbol{\nabla} \cdot \mathbf{V}_{i}+\mathbf{W}_{h_{i}}
$$

where the entrainment term is

$$
\mathbf{W}_{h_{i}}= \begin{cases}\omega_{e} & \text { for } i=1 \\ -\omega_{e} & \text { for } i=2 \\ 0 & \text { otherwise }\end{cases}
$$

Note that changes in the temperature in this model are due to advection and, in the case of the mixed layer and upper thermocline, entrainment. The effects of surface fluxes, evaporation, and precipitation in the thermodynamic equation are neglected because of their comparatively weaker influence than that of entrainment in the heat budget. With these assumptions, the thermodynamic equation is simply

$$
\frac{\partial T_{i}}{\partial t}=\mathbf{v}_{i} \cdot \boldsymbol{\nabla} T_{i}+W_{T_{i}}
$$

with

$$
W_{T_{i}}= \begin{cases}\frac{\omega_{e}}{h_{1}}\left(T_{2}^{\prime}-T_{1}\right) & \text { for } i=1 \\ \frac{\omega_{e}}{h_{2}}\left(T_{2}-T_{2}^{\prime}\right) & \text { for } i=2 \\ 0 & \text { otherwise }\end{cases}
$$

where $T_{2}^{\prime}$ is the temperature at the top of layer 2 . Here $T_{2}^{\prime}$ is diagnosed from the layer-mean values and those at the bottom of layer 2 by the assumption of linear profiles within each layer. The temperature at the bottom of layer 2 can only be changed by advection and therefore remains constant in horizontally homogenous initial conditions.

In the coupling procedure, the ocean model is forced by a two-dimensional surface wind field constructed from the axisymmetric flow in the hurricane translation velocity. In turn, the hurricane model is forced by an axisymmetric SST field constructed through azimuthal averaging of the two-dimensional SST field of the ocean model around the storm center. The respective boundary fields are updated each time step. Even though the TC intensity can be affected by the asymmetric process, Schade and Emanuel (1999) have shown that the axisymmetric approximation is valid to provide a first-order evaluation of the ocean's feedback to the TC intensity.

\section{b. Experiment design}

The foci of this study are to address the effects of the ocean eddy on TC intensity. To isolate the scientific issues and to simplify the physical interpretations, here the atmospheric environment and the initial vortex structure are fixed to discuss the role of the oceanic environment. Each experiment is started with initial low-pressure disturbance with the maximum azimuthal wind speed of $17 \mathrm{~m} \mathrm{~s}^{-1}$, the radius of the maximum wind of $100 \mathrm{~km}$, the minimum sea level pressure of 1003 $\mathrm{hPa}$, and the translation speed of $5 \mathrm{~m} \mathrm{~s}^{-1}$. The distributions of the azimuthal wind speed and the sea level pressure satisfy the conservation of the angular momentum and the gradient wind balance. Other atmospheric environmental parameters are shown in Table 1. The experiments are detailed in the following sections.

\section{1) Experiment A: Impact of the Assimilated PROFILES OF THE NorTh PACIFIC OCEAN NOWCAST/FORECAST SYSTEM}

We use five different vertical temperature profiles obtained from the North Pacific Ocean Nowcast/ Forecast System (NPACNFS) of the Naval Research Laboratory (NRL; Ko et al. 2003) before Maemi (2003) passed the warm eddies (Lin et al. 2005) in the eddy rich zone $\left(18^{\circ}-25^{\circ} \mathrm{N}, 122^{\circ}-160^{\circ} \mathrm{E}\right.$; Qiu 1999$)$ as the initial oceanic structure to assess how these different underlying oceanic profiles might affect the TC intensity. Details of these profiles are given in section 3. The SST feedback factor, $F_{\text {SST }}$ (Schade and Emanuel 1999), is used to discuss the ocean's negative feedback with different upper-oceanic thermal structures; that is,

$$
F_{\mathrm{SST}}=\frac{\Delta p_{\text {coupled }}}{\Delta p_{\text {uncoupled }}}-1,
$$

where $\Delta p$ is the difference between the final steady state and the initial minimum sea level pressure in the eye of the storm [note that this is different from the definition by Schade and Emanuel (1999), which is the pressure difference in the storm center and in the environment]. The subscripts "coupled" and "uncoupled" 
TABLE 1. Control value of the input parameters of the hurricane model.

\begin{tabular}{|c|c|c|}
\hline Symbol & Initial conditions & Control value \\
\hline$v_{\max }$ & Initial maximum azimuthal wind & $17 \mathrm{~m} \mathrm{~s}^{-1}$ \\
\hline$r_{\max }$ & Initial radius of maximum wind & $100 \mathrm{~km}$ \\
\hline$r_{\text {outer }}$ & $\begin{array}{l}\text { Outer edge of initial vortex } \\
\text { Ambient conditions }\end{array}$ & $500 \mathrm{~km}$ \\
\hline$T_{s_{a}}$ & Unperturbed sea surface temperature & $29^{\circ} \mathrm{C}$ \\
\hline$H_{a}^{a}$ & Initial boundary layer relative humidity & $80 \%$ \\
\hline$s_{L_{a}}$ & Ambient moist entropy in lower-tropospheric layer & $s_{B a}-20 \mathrm{~J} \mathrm{~kg}^{-1} \mathrm{~K}^{-1}$ \\
\hline$f^{2 a}$ & Coriolis parameter & $5 \times 10^{-5} \mathrm{~s}^{-1}$ \\
\hline$p_{a}$ & $\begin{array}{l}\text { Ambient surface pressure } \\
\text { Physical parameters }\end{array}$ & $1013 \mathrm{hPa}$ \\
\hline rad & Radiative relation parameter & $9 \times 10^{5} \mathrm{~s}^{-1}$ \\
\hline$l^{2}$ & Mixing length & $6 \times 10^{-4} \delta R^{2}$ \\
\hline$\left.\frac{\Gamma_{\text {moist }}}{\Gamma_{\text {dry }}}\right|_{o}$ & Lapse rate ratio at the top of the $\mathrm{BL}$ & 0.4 \\
\hline$\left.\frac{\Gamma_{\text {moist }}}{\Gamma_{\text {dry }}}\right|_{m}$ & Lapse rate ratio at the midlevel & 0.5 \\
\hline$\left.\frac{\partial s_{d}}{\partial P}\right|_{m}$ & Dry lapse rate at the midlevel & $-0.003 \mathrm{~J} \mathrm{~kg}^{-1} \mathrm{~K}^{-1} \mathrm{~Pa}^{-1}$ \\
\hline & Numerical parameters & \\
\hline$\delta t_{H}$ & Time step & $30 \mathrm{~s}$ \\
\hline$N_{R}$ & Number of $R$ surfaces & 46 \\
\hline$\delta z$ & Height of the model top & $16 \mathrm{~km}$ \\
\hline$\delta T_{L}$ & Temperature depth of the lower-tropospheric layer & $23^{\circ} \mathrm{C}$ \\
\hline$\delta T_{U}$ & Temperature depth of the upper-tropospheric layer & $72^{\circ} \mathrm{C}$ \\
\hline$\delta p_{B}$ & Pressure depth of the BL & $100 \mathrm{hPa}$ \\
\hline$\delta p$ & Pressure depth of the tropospheric layer & $375 \mathrm{hPa}$ \\
\hline
\end{tabular}

mean the coupled run and the uncoupled run, respectively. This factor is always negative because the ocean feedback would always reduce the storm intensity.

\section{2) EXPERIMENT B: Sensitivity tests of SOME KEY PARAMETERS}

We conduct a sensitivity test to evaluate the impact of the following four parameters revealing the upperoceanic thermal structure on TC intensity: the SST (this also represents the temperature of the mixed layer), the mixed layer depth, the temperature jump at the base of the mixed layer $(\Delta T)$, and the lapse rate of the upper thermocline (this represents the stratification below the mixed layer). This experiment is expected to help us identify the parameter to which the TC intensity is most sensitive.

\section{3) ExPeriment C: Evaluation of the eddy's ROLE}

Experiments are conducted to evaluate the evolution of the TC when a different oceanic thermal structure is introduced to the model at a different stage of the TC development. To quantify the eddy's contribution to the intensity feedback, the eddy feedback factor is defined as $F_{\text {EDDY-s }}$; that is,

$$
F_{\text {EDDY-S }}=\frac{\Delta p_{\text {EDDY }}}{\Delta p_{\text {NO_EDDY }}}-1,
$$

where $\Delta p$ is the same as that defined in Eq. (15), while the subscript "NO_EDDY" indicates that the TC does not encounter an ocean eddy, and the index "EDDY" represents the opposite. The subscript "-S" indicates the TC encounters a perpetual ocean eddy. Note that $F_{\text {EDDY-S }}$ would be positive (negative) when the TC encounters the warm (cold) eddy. Meanwhile, the larger the magnitude of $F_{\text {EDDY-S }}$, the stronger the impact of the eddy.

However, the eddy feedback effect is transient in reality. To include the impact of interaction time scale, we allow a storm to enter a 700-km-wide warm eddy and then return to the standard oceanic structure for the rest of the model integration. The other eddy feedback factor, $\mathrm{F}_{\mathrm{EDDY}-\mathrm{T}}$, is defined as

$$
F_{\text {EDDY-T }}=\frac{\Delta p_{\text {out }}-\Delta p_{\text {in }}}{\Delta p_{\text {in }}},
$$

where $\Delta p_{\text {in }}\left(\Delta p_{\text {out }}\right)$ is the amount of the sea level central pressure deepening at the moment when the storm encounters (leaves) the ocean eddy. The subscript "-T" indicates the TC only passes an ocean eddy for a finite 

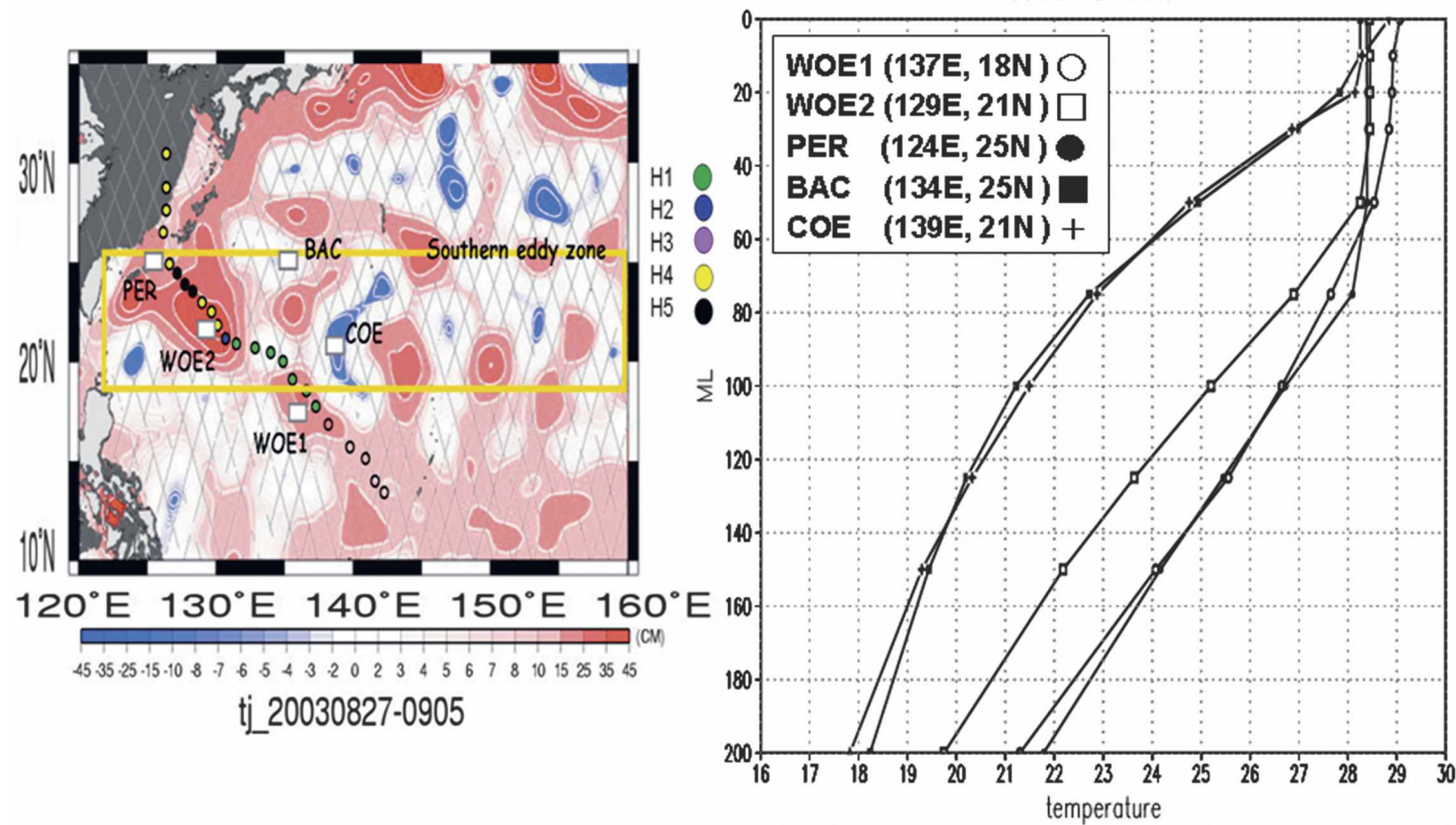

FIG. 1. (a) Composite of NASA's TOPEX/Poseidon and Jason-1 measurements showing the pre-Maemi sea surface height anomaly (SSHA) for one cycle (10 days) between 27 Aug and 5 Sep 2003. Maemi's trajectory and location of the southern eddy zone is overlaid. As the current altimetry algorithm is less accurate in the shallow waters, the SSHA measurements in regions of bathymetry $<200 \mathrm{~m}$ are not used and are shown in dark gray (Fu and Cazenave 2001). The land areas are shaded in light gray (Fig. 1 of Lin et al. 2005). (b) Vertical temperature profiles from the NRL's NPACNFS model output showing WOE1 and WOE2, COE, PER, and BAC.

(transient) period. Likewise, $F_{\text {EDDY-T }}$ could be positive (warm eddy) or negative (cold eddy). The eddy feedback factor of $F_{\text {EDDY-T }}=0.5$ represents that the storm's intensity is further strengthened by $50 \%$ because of the encounter with the warm ocean eddy.

\section{Results and discussions}

\section{a. Experiment A: Impact of the assimilated profiles on the NPACNFS}

Because of the lack of in situ upper-ocean temperature profiles over the northwestern Pacific, in experiment A, five NPACNFS profiles at different locations (as shown in Fig. 1a) on 5 September 2003 (as reported in Lin et al. 2005) were used to represent various states of upper-oceanic thermal structure. Warm ocean eddies 1 and 2 (WOE1 and WOE2) represent two different warm eddies, while cold ocean eddy (COE) refers to the cold eddy near or on the passage of Maemi. Periphery (PER) and background (BAC) display the structure on the periphery of the southern eddy zone and the background reference, respectively. The oceanic ther- mal structures of these five locations (Fig. 1b) are used as the initial ocean conditions for the model integration.

In the uncoupled experiments, the steady-state $\mathrm{TC}$ intensities with these five oceanic structures are at a close range of $5 \mathrm{hPa}$ to one another. The small difference only results from the use of different initial SST values (solid line of Fig. 2). On the other hand, the TC intensities in the coupled experiments (dashed line of Fig. 2) deviate significantly from one anther, because of the highly divergent magnitude of the negative feedback associated with the different initial oceanic structure. Using the WOE2's oceanic structure, the storm intensifies with time, develops, and finally reaches the steady state at $955 \mathrm{hPa}$ (Fig. 2), with the value of $F_{\text {SST }}$ of -0.24 . However, the same disturbance would reach the steady state at $984 \mathrm{hPa}$, with the $F_{\mathrm{SST}}$ of -0.72 , when the COE profile is used. This result shows that in the WOE2's (COE's) oceanic thermal structure, the ocean's negative feedback can reduce storm's intensity by $24 \%(72 \%)$ as described in Eq. (15).

Clearly, the preceding results show that warm and cold ocean features result in very different storm inten- 


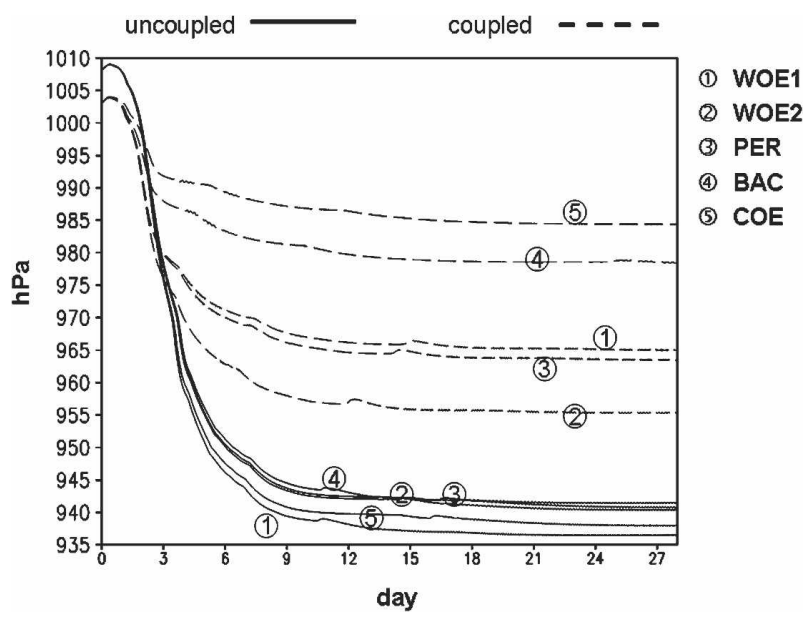

FIG. 2. Time series of central pressure with different initial oceanic conditions (as shown in Fig. 1b). The solid (dashed) lines represent results of the uncoupled (coupled) experiments.

sity responses in this simple coupled model. According to Cione and Uhlhorn (2003), the changes in inner-core SST can dramatically alter air-sea fluxes within the high-wind inner-core storm environment which provides links to the ocean's negative feedback and TC intensity. In this experiment, there is a fairly linear relation between the value of $F_{\mathrm{SST}}$ and the storm-induced SST reduction in the core area of a storm (indicated as $\Delta \mathrm{SST}_{\text {in }}$; Fig. 3). The results agree with Cione and Uhlhorn (2003).

\section{b. Experiment B: Sensitivity tests of some key parameters}

The sensitivity tests of atmosphere-related parameters in this model have been conducted by Schade and Emanuel (1999). In this paper, we focus on the sensitivity tests of different ocean parameters on TC intensity. Following Fig. 1b, we investigate the impact of the following four upper-oceanic thermal parameters; namely, the SST (this also represents the temperature in the mixed layer in this model), the mixed layer depth, the temperature jump at the base of the mixed layer $(\Delta T)$, and the lapse rate of upper thermocline (this represents the stratification below the mixed layer). The range of these four parameters in this experiment is chosen from the typical observed values and converted into the model.

The range of the SST is from $26^{\circ}$ to $32^{\circ} \mathrm{C}$. It is recognized that $26^{\circ} \mathrm{C}$ is the threshold for TC genesis, while $32^{\circ} \mathrm{C}$ is the upper bound of SST in the northwestern Pacific basin. The control (default) value of SST in the model is $29^{\circ} \mathrm{C}$. The range of mixed layer depth is from 10 to $80 \mathrm{~m}$, and this is chosen from the NPACNFS

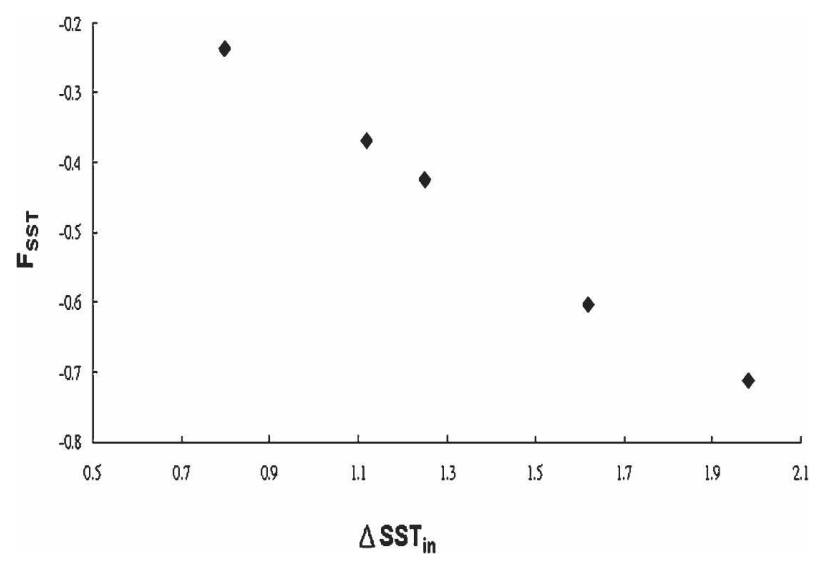

FIG. 3. Scatterplot of the value of SST feedback factor $\left(F_{\mathrm{SST}}\right)$ as a function of the SST reduction $\left(\Delta \mathrm{SST}_{\mathrm{in}}\right)$ in the center of the eye.

model output of the mixed layer depth from cold to warm eddies in the northwestern Pacific basin in the mid- to low latitudes. The control value of the mixed layer depth is $40 \mathrm{~m}$. Unlike the SST and mixed layer depth, the $\Delta T$ is simply a parameter in this particular numerical model. A small jump in temperature is set across the base of the mixed layer initially, so that the $R_{v}$ [Eq. (10)] will not be vanishingly small during the first time step of the numerical integration. The range of the $\Delta T$ here is from 0.1 to 0.8 to address its influence on the performance of this coupled model. The control value of $\Delta T$ is $0.2^{\circ} \mathrm{C}$. Similar to the range of the mixed layer depth, the range of the lapse rate of the upper thermocline is also chosen from the NPACNFS's ocean features of warm and cold eddies, and the control value is $0.06^{\circ} \mathrm{C} \mathrm{m}^{-1}$.

The control values of these four parameters are specified as the "Ctrl run" of the oceanic thermal structure. The minimum central sea level pressure at steady state of the Ctrl run is $969 \mathrm{hPa}$, with the corresponding $F_{\text {SST }}$ of -0.56 .

\section{1) IMPACT FROM THE SST}

By fixing all other parameters, it is shown that for the increase of SST every degree, a 2-hPa deeper steadystate minimum central sea level pressure is obtained (dashed line of Fig. 4). Obviously, the SST is less sensitive to TC intensity in the coupled experiments than in the uncoupled experiments, which has a 6-hPa deeper steady-state minimum sea level pressure for the increase of SST every degree. This result highlights the role of the coupled model in modulating the sensitivity of the SST values when the feedback from the storminduced cold wake is considered. This argument can be further elaborated by Fig. 5, which shows the time se- 


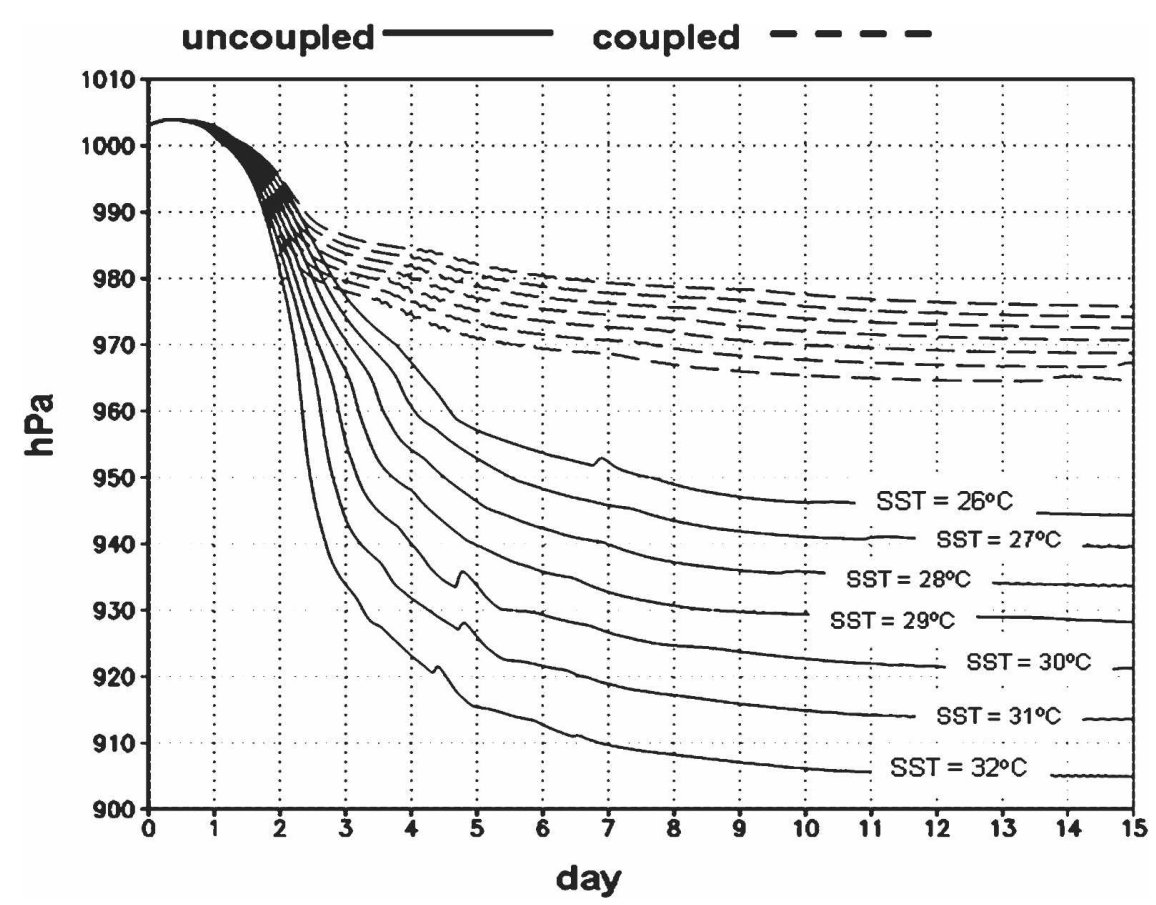

FIG. 4. Time series of the central pressure with different initial SST. The solid (dashed) lines represent the uncoupled (coupled) experiments. The steady-state central sea level pressure in both uncoupled and coupled experiments drops as the initial SST increases from $26^{\circ}$ to $32^{\circ} \mathrm{C}$.

ries of the SST reduction in the storm center in two experiments with the initial SSTs of $26^{\circ}$ and $32^{\circ} \mathrm{C}$, respectively. Apparently, stronger SST reduction is induced in the experiment of $32^{\circ} \mathrm{C}$ than $26^{\circ} \mathrm{C}$. In other words, while stronger cooling is induced for stronger storms with higher initial SST, this negative feedback provides a constraint to the difference of the storm intensity from different initial SSTs. This result can also be verified from the value of $F_{\mathrm{SST}}$, while a higher initial SST corresponds to a greater negative value of $F_{\text {SST }}$ (see Fig. 6a).

\section{2) IMPACT OF THE MIXED LAYER DEPTH}

Entrainment is a dominant process in the mixed layer's heat budget of this model. It brings colder water from the upper thermocline to the mixed layer and thus reduces the temperature in the mixed layer. Other effects, such as advection and pumping, do little in altering the storm's intensity, except for the slowly moving storm (Korty 2002). In this coupled model, the entrainment term is shown in Eq. (8) and the entrainment velocity is parameterized with an inverse power of the bulk Richardson number as in Eqs. (9) and (10). Thus, the impact of cold water entrained to the mixed layer from the upper thermocline is smaller in the ocean with the thicker mixed layer than in the shallower one.
When the mixed layer is shallower, the current velocity generated by the surface stress is stronger and the velocity shear at the base of the mixed layer is higher. Eqs. (9) and (10) show that stronger entrainment velocity would be induced with stronger velocity shear,

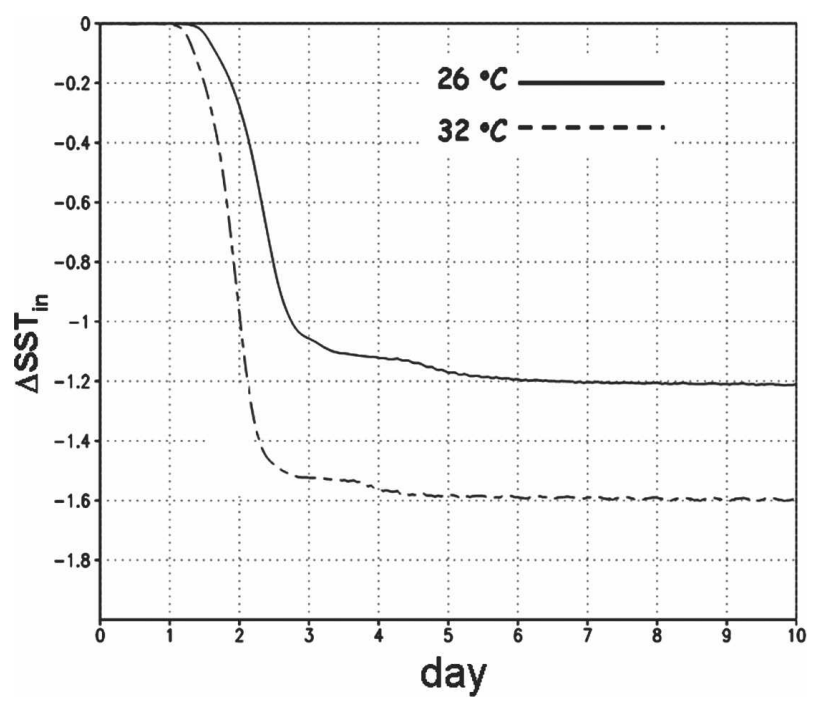

FIG. 5. Time series of the values of the SST reduction $\left(\Delta \mathrm{SST}_{\mathrm{in}}\right)$ for experiments with the initial SST of $32^{\circ} \mathrm{C}$ (dashed line) and $26^{\circ} \mathrm{C}$ (shaded line), respectively. 
(a)

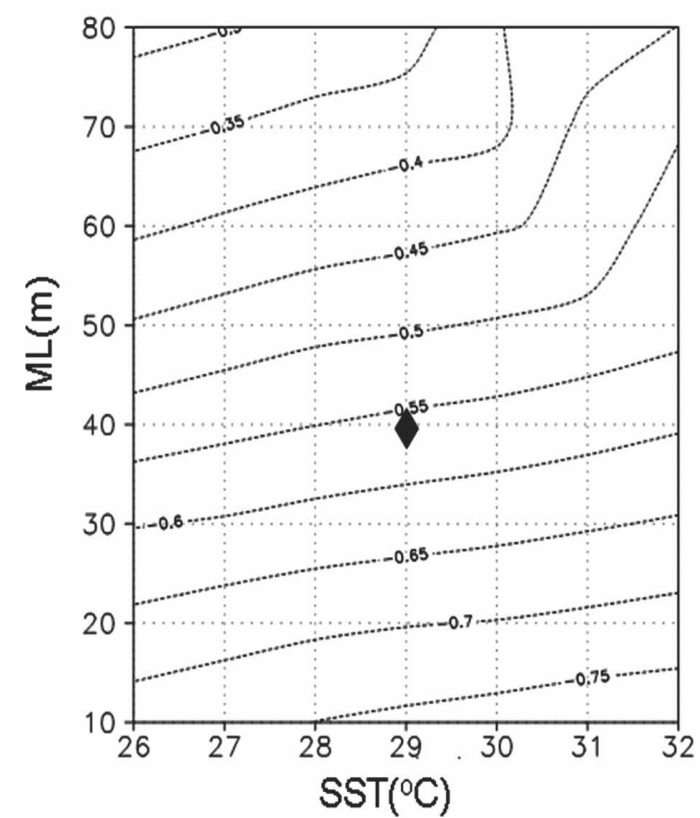

(b)

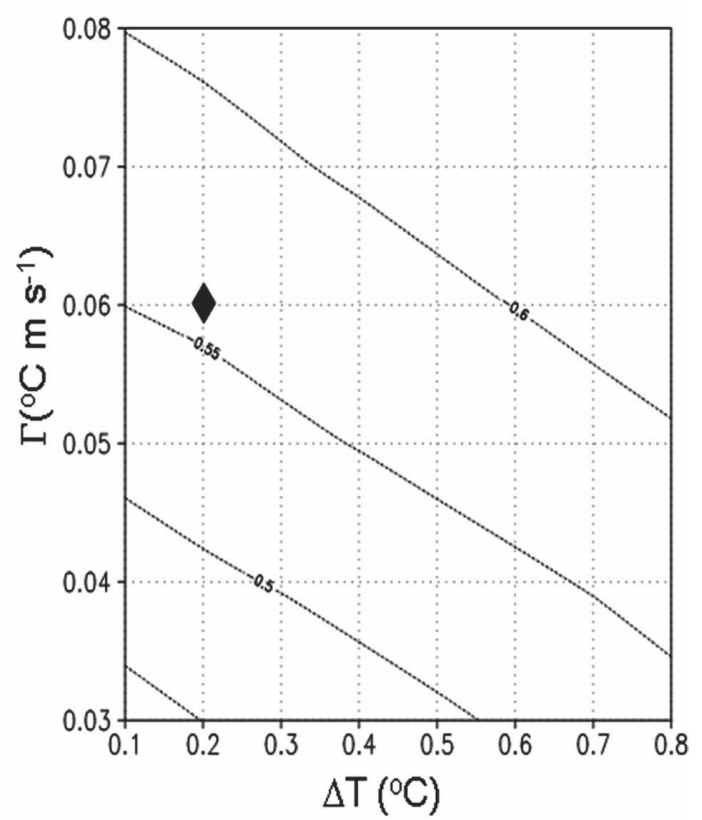

FIG. 6. (a) The ocean's negative feedback factor $\left(F_{\text {SST }}\right)$ as a function of SST, mixed layer depth. (b) Same as in (a) but a function of temperature jump at the base of the mixed layer $(\Delta T)$, and the temperature lapse rate below the mixed layer $(\Gamma)$. The interval is $5 \%$ and the diamond symbol indicates the corresponding values of the control experiment.

shallower mixed layer depth, and a lower density jump between the mixed layer and the upper thermocline. In addition, if the mixed layer is thicker, the cold water entrained from upper thermocline will be diluted in a larger volume of fluid, thus weakening the SST cooling. The sensitivity of the mixed layer to the TC intensity is a $4.7-\mathrm{hPa}$ deepening of the steady-state minimum sea level pressure for every $10-\mathrm{m}$ increase of the mixed layer depth. A near-linear relation is identified (Fig. 6a) between the magnitude of the SST feedback factor $\left(F_{\mathrm{SST}}\right)$ and the mixed layer depth. Interestingly, a somewhat different regime of $F_{\mathrm{SST}}$ emerges when the SST exceeds $30^{\circ} \mathrm{C}$ or the depth of the mixed layer exceeds $60 \mathrm{~m}$.

\section{3) The IMPACt of $\Delta T$ AND THE LAPSE RATE OF UPPER THERMOCLINE}

Similar to the effect from the mixed layer depth, $\Delta T$ and the lapse rate of upper thermocline also affect the $\mathrm{TC}$ intensity through the entrainment process. It is found that both larger $\Delta T$ and the thermocline lapse rate result in smaller entrainment velocity due to the larger density jump in Eq. (10). However, more SST reduction would be induced associated with the colder water entrained [see Eqs. (13) and (14)] from the upper thermocline when the $\Delta T$ and the thermocline lapse rate is larger. The preceding two mechanisms obviously work simultaneously in the opposite direction, and in this coupled model the latter one works more significantly and leads to stronger SST feedback. The sensitivities of them are a -0.7 - and $-2.5-\mathrm{hPa}$ deepening of the steady-state minimum sea level pressure with respect to every $0.1^{\circ} \mathrm{C}$ increase of $\Delta T$ and every $0.01^{\circ} \mathrm{C}$ $\mathrm{m}^{-1}$ increase of the lapse rate of upper thermocline. Again, a near-linear relation is identified (Fig. 6b) between the magnitude of the SST feedback factor $\left(F_{\mathrm{SST}}\right)$ and both $\Delta T$ and the thermocline lapse rate.

To make a fair comparison of the sensitivity of the TC intensity change to the previously mentioned four different parameters, which are in different units, we vary each parameter by $10 \%$ of its range (mentioned above). The results show that the response of each steady-state sea level minimum pressure deepens about $1.2,3.3,-0.49$, and $-1.25 \mathrm{hPa}$ with respect to the $10 \%$ increase of the range of the SST, the mixed layer depth, the $\Delta T$, and the lapse rate of the upper thermocline, respectively. The mixed layer depth appears the most sensitive parameter of the upper-ocean structure to the 


\section{$\begin{array}{ll}\text { (a) Standard oceanic structure (b) Eddy structure } & \text { (b) }\end{array}$}

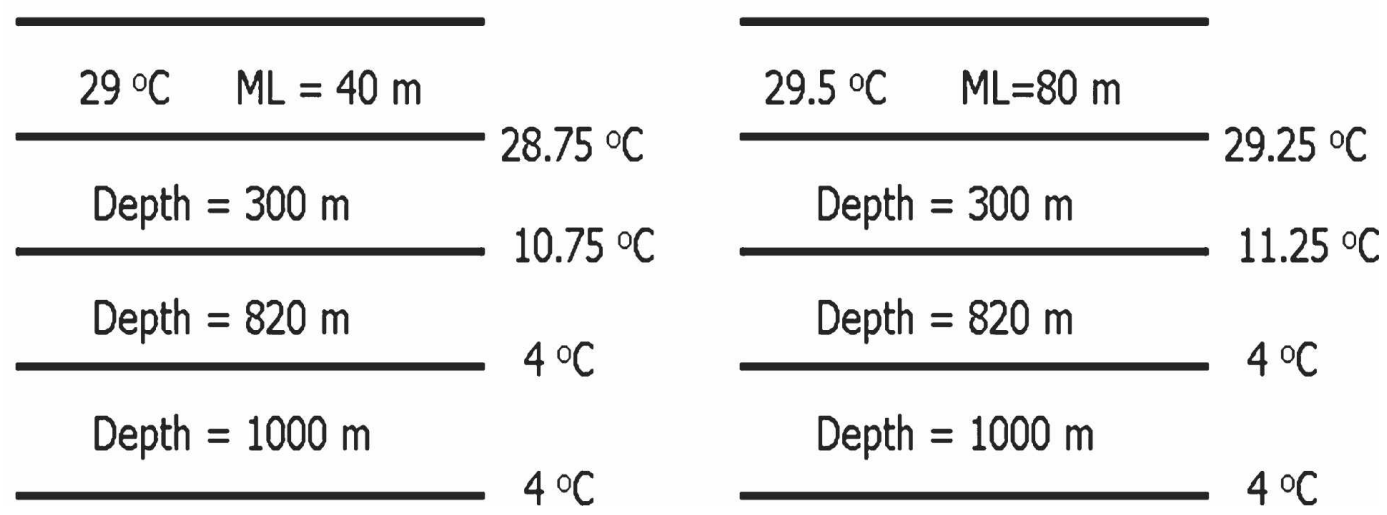

FIG. 7. Illustrated profiles of the (a) standard oceanic structure and (b) eddy structure.

TC intensity, while the $\Delta T$ is the least sensitive one. One thing to keep in mind is that the result of sensitivity tests depends on the control values of the atmospheric and oceanic environment parameters. More experiments may be needed to examine the range of the above sensitivity.

\section{c. Experiment C: Evaluation of the eddy's role}

\section{1) TC ENCOUNTERING THE PERPETUAL OCEAN EDDY}

In the preceding experiments, we have tested the sensitivities of the parameters of the upper-oceanic thermal structure on TC intensity and on the ocean's negative feedback. In this section, we first conduct a NO_EDDY experiment with the standard oceanic condition without the eddy. Then, to highlight the influence from the ocean eddy, we run other experiments with a storm embedded in the eddy environment and examine the impact from the ocean eddy. Both the standard oceanic thermal structure (NO_EDDY experiment) and the specified eddy's thermal structures are depicted in Fig. 7. Note that the SST (mixed layer depth) is increased by $0.5^{\circ} \mathrm{C}(40 \mathrm{~m})$ in the eddy structure as compared to the standard oceanic structure, while the $\Delta \mathrm{T}$ and the lapse rate of the upper thermocline remain the same. To keep the model stable, the transition distance between two different ocean structures is $200 \mathrm{~km}$. Experiments are performed to switch the ocean to the eddy conditions at different integration times (such as on the days $0,1,5,10$, and 15 , represented with "EDDY_0", "EDDY_1", "EDDY_5", "EDDY_10", and "EDDY_15" respectively).

As shown in Fig. 8, the steady-state minimum sea level pressures of a storm encountering the eddy at different integration times all reach $947 \mathrm{hPa}$, which is 27
hPa deeper than that from the NO_EDDY experiment. The results suggest that in this coupled model the steady-state intensity of a storm in the eddy environment does not depend on when the ocean is switched to the eddy condition. Note that the intensification rate increases suddenly after a storm encounters the eddy. In the EDDY_5 experiment, the storm intensifies from 978 to $960 \mathrm{hPa}$ in two days (from day 5 to day 7) while in the NO_EDDY experiment it only intensifies by about $3 \mathrm{hPa}$ during that period.

To interpret these results, we can see the entropy flux diagram at the integration period from day 5 to day 7

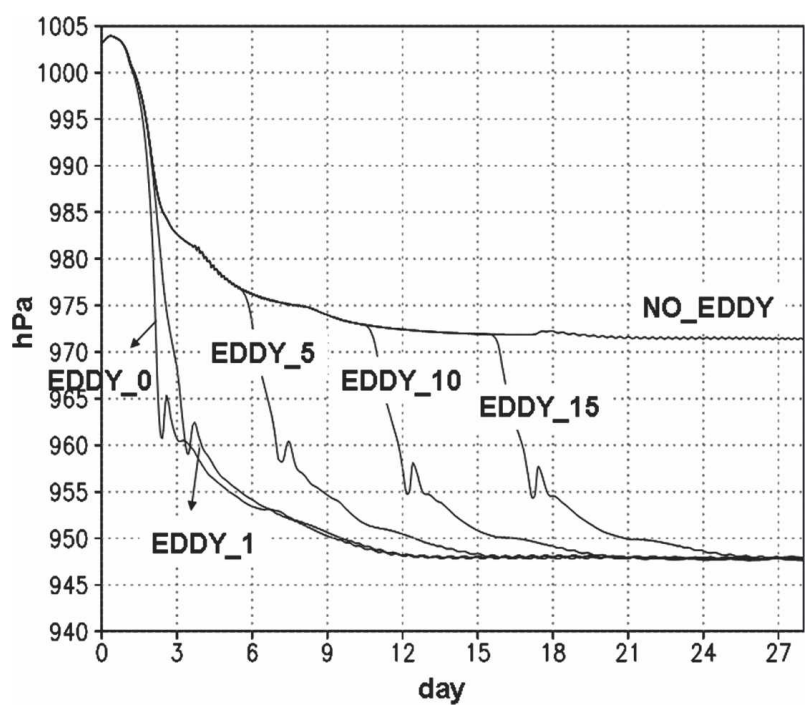

FIG. 8. Time series of the central pressure in the perpetual-eddy experiments. "NO_EDDY" indicates the experiment with the standard oceanic condition without the eddy. "EDDY_\#" indicates the experiments where the ocean conditions are switched to the eddy's structure at the \#th day of the model integration. 


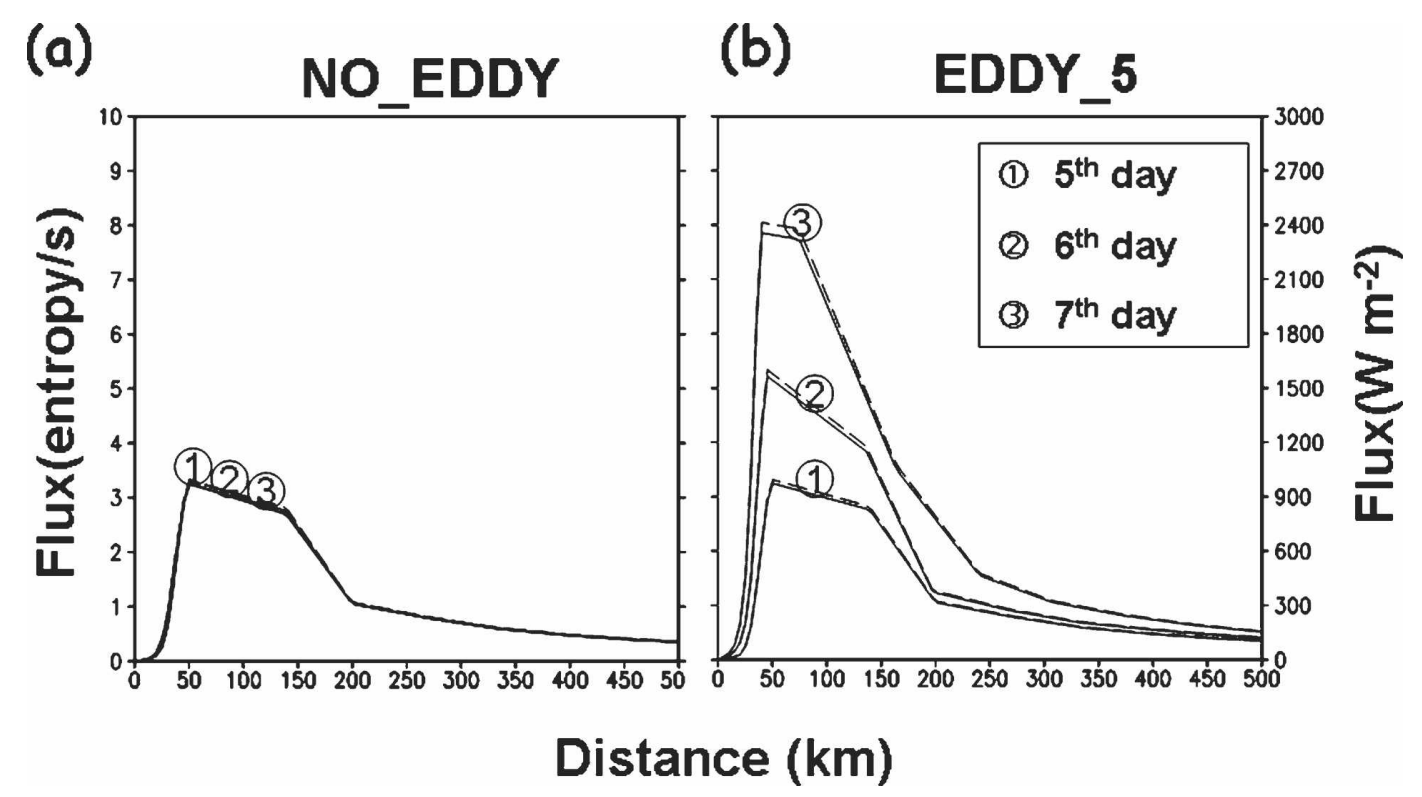

FIG. 9. (a) Entropy flux (solid line, $\mathrm{J} \mathrm{kg}^{-1} \mathrm{k}^{-1} \mathrm{~s}^{-1}$ ) and the corresponding enthalpy flux (dashed line, $\mathrm{W} \mathrm{m}^{-2}$ ) at different integration times in the NO_EDDY experiment. (b) Same as in (a) but in the EDDY_5 experiment.

(Fig. 9). Obviously, the entropy flux in the EDDY_5 experiment increases quickly and nearly doubles two days after the storm encounters the eddy, but that in the NO_EDDY experiment almost remains unchanged. This rapid increase of the entropy flux in the EDDY_5 experiment could be attributed to both the additional heat flux supplied by the warm eddy and to the decreased SST cooling induced in the eddy's structure.

Figure 10 describes the mixed layer temperature distribution (shaded) in the EDDY_5 experiment and the difference of the reduction of SST between the EDDY_5 experiment and the NO_EDDY experiment (contour) on days 7 and 8 when the storm has developed in the eddy structure for a period. The solid line (dashed line) in Fig. 10 indicates that the SST cooling in the EDDY_5 experiment is stronger (weaker) than that in the NO_EDDY experiment. On day 7, the SST cooling in the EDDY_5 experiment is weaker than that in the NO_EDDY experiment except in the trailed righthand side wake region. On day 8 the stronger SST cooling in the trailed-wake region in the EDDY_5 experiment is more prominent and extensive. The cause of this strong cooling in the wake region could be the stronger entrainment effect associated with the stronger storm intensity under the higher SST in the eddy structure. In other words, there are two oceanic responses when a storm enters the eddy:

(i) Deeper mixed layer depth restricts the entrainment and SST cooling as we have discussed in section $3 \mathrm{~b}$, thus reducing the induced SST cooling in the center of the storm, which is consistent with the insulation effect as described in Lin et al. (2005).

(ii) Higher SST leads to a stronger storm accompanied by the higher wind speed that induces larger current velocity shear. This response leads to a strong mixing of surface water and upwelling of deeper and cooler water, and is more evident to the right of the storm's track.

These two responses are both governed by the entrainment effect, but they compete with each other and result in different oceanic responses at each location. According to Cione and Uhlhorn (2003), only the SST cooling within the inner region can significantly impact storm intensity, so this stronger SST cooling in the trailed-wake region in the eddy run does not have an adverse effect on storm intensification. This result is consistent with $\mathrm{Wu}$ et al. (2005), which showed that only the symmetric SST anomalies in the inner region can significantly and directly affect storm intensity.

To understand the efficiency of the eddy feedback to TC intensity with respect to different eddy structure, we define an eddy feedback factor, $F_{\text {EDDY-S }}$, as shown in Eq. (16). Figure 11 is the value of $F_{\text {EDDY-S }}$ as the function of SST and mixed layer depth in the eddy structure while the storm's translation speed is $2.5 \mathrm{~m} \mathrm{~s}^{-1}$. Clearly, $F_{\text {EDDY-s }}$ increases with rising eddy's SST and deepening mixed layer depth. In addition, the relation between the $F_{\text {EDDY-s }}$ and the translation speed is also assessed in this section (Fig. 12). The tendency of $F_{\text {EDDY-s }}$ with the increase of the translation speed is not 


\section{7 day}

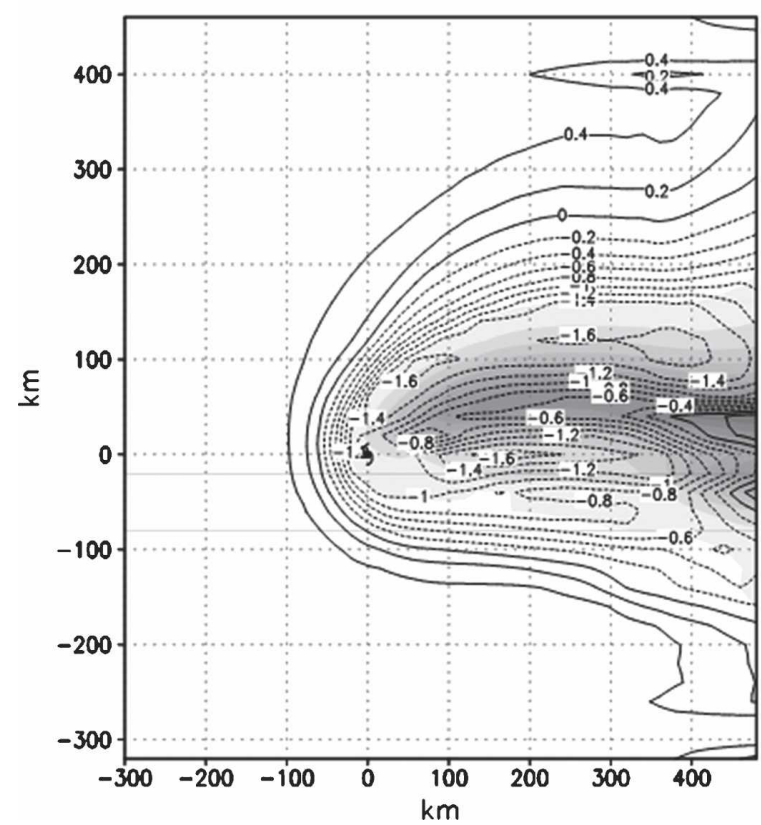

\section{8 day}

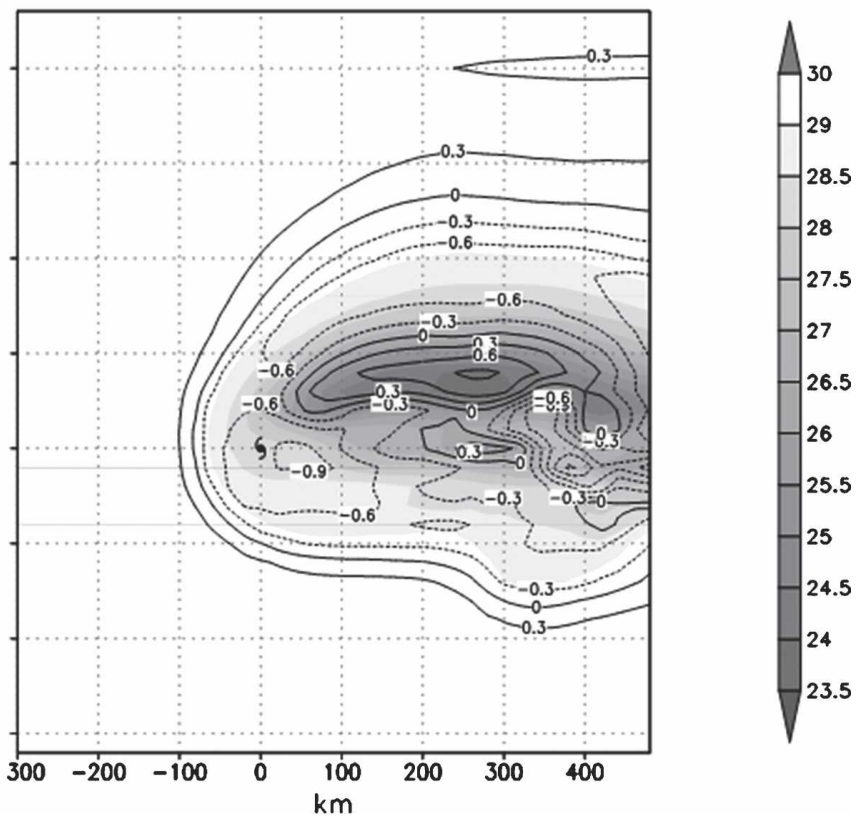

FIG. 10. (a) The snapshot of sea surface temperature (shaded) on day 7 of the EDDY_5 experiment. (b) Same as in (a), but on day 8. The contour indicates the reduction of the sea surface temperature in the EDDY_5 experiment subtracted by that in the NO_EDDY experiment. The solid (dashed) line represents the positive (negative) values, indicating that the SST cooling in the EDDY_5 experiment is stronger (weaker) than that in the NO_EDDY experiment.

linear when the translation speed is lower than $5 \mathrm{~m} \mathrm{~s}^{-1}$. This counterintuitive result could be attributed to the definition of the $F_{\text {EDDY-S }}$, which involves the final steady-state intensity and thus includes positive effects of reducing the ocean's negative feedback due to both the translation speed and the warm eddies' conditions. In other words, in the perpetual-eddy experiment the influence of the translation speed on eddy feedback effect is masked. Besides, here we only show the impact on the TC intensity when it encounters a perpetual ocean eddy. In reality, the TC would only pass the ocean eddy for a finite time, and thus the response would be different.

\section{2) TC ENCOUNTERING A TRANSIENT OCEAN EDDY}

To clarify the effect of the ocean eddies and to consider the impact when the TC encounters the ocean eddy for finite time, we let a storm enter a 700-km-wide warm ocean eddy and then return to the standard oceanic structure for the rest of the model integration. The standard oceanic thermal structure and the specified eddy's thermal structure are again depicted in Fig. 7. In this experiment, we switch the ocean to the eddy conditions on day 5 , so that the storm encounters the eddy on day 5.5 and leaves it on day 7.2 (because the trans-

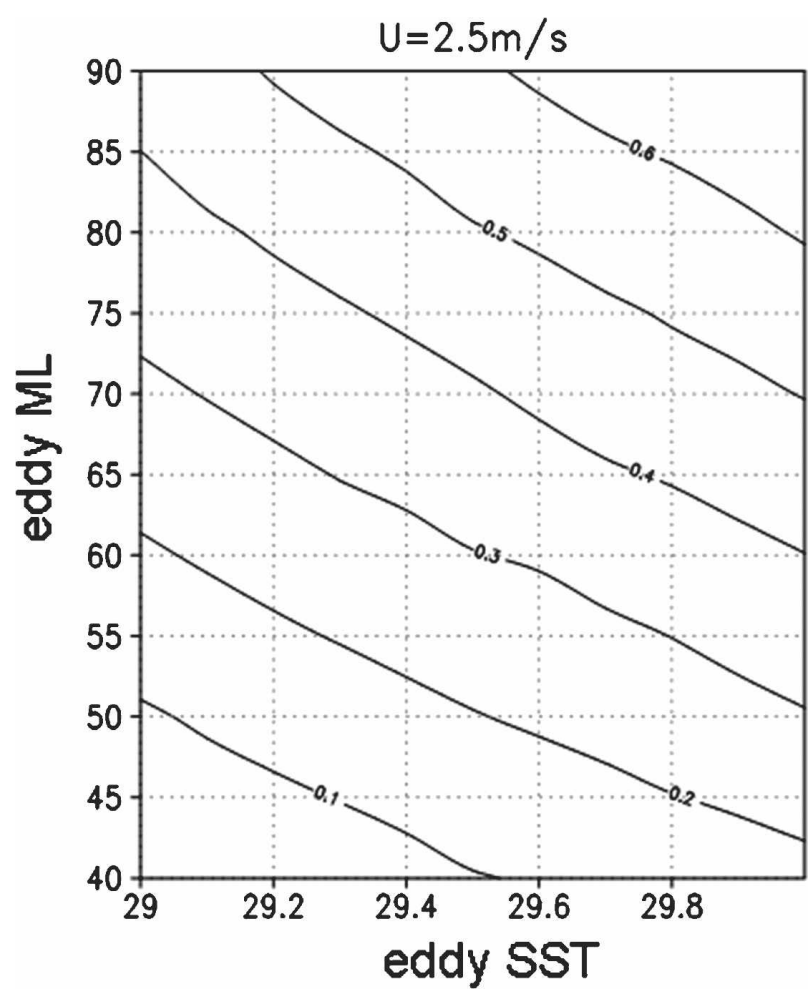

FIG. 11. $F_{\text {EDDY-s }}$ as a function of the eddy's SST and mixed layer depth. 


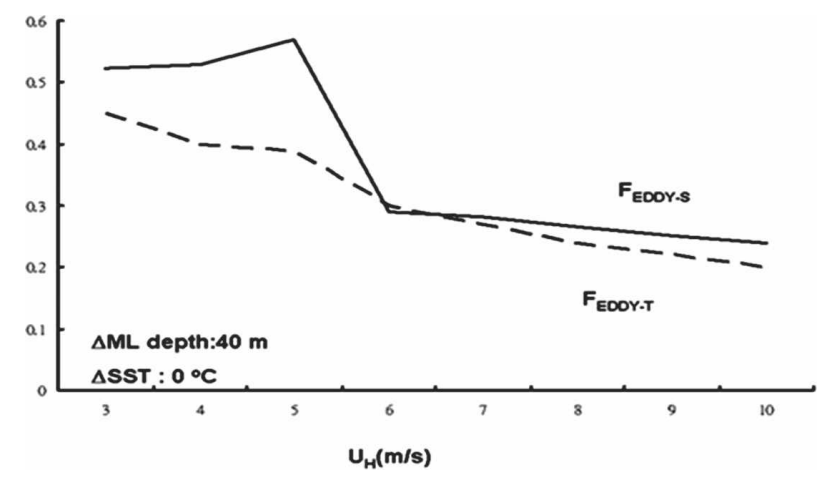

FIG. 12. $F_{\text {EDDY-S }}$ (solid line) and $F_{\text {EDDY-T }}$ (dashed line) as a function of the translation speed $\left(U_{H}\right)$. Here $\Delta \mathrm{ML}$ and $\triangle \mathrm{SST}$ account for the differences of the mixed layer and SST between the standard ocean and the warm eddy.

lation speed is $5 \mathrm{~m} \mathrm{~s}^{-1}$ ). Figure 13 shows the time series of the sea level central pressure and the maximum azimuthal wind. The TC strengthens from 978 to $962 \mathrm{hPa}$ (45 to $56 \mathrm{~m} \mathrm{~s}^{-1}$ ) during the episode when it moves across the warm eddy. The difference of $\Delta p_{\text {in }}$ and $\Delta p_{\text {out }}$ in Fig. 13 represents the magnitude of the intensification due to the presence of the ocean eddy. The new transient eddy feedback factor, $F_{\text {EDDY-T }}$, is defined in Eq. (17). In Fig. 13, the value of $F_{\text {EDDY-T }}$ is 0.64 , which represents that the storm's intensity (when it leaves the eddy), as measured by the pressure depression, is strengthened by $64 \%$ due to an encounter with the warm ocean eddy. Like $F_{\text {EDDY-S }}, F_{\text {EDDY-T }}$ could be positive (warm eddy) or negative (cold eddy).

Figure 14 depicts the value of the $F_{\text {EDDY-T }}$ as the

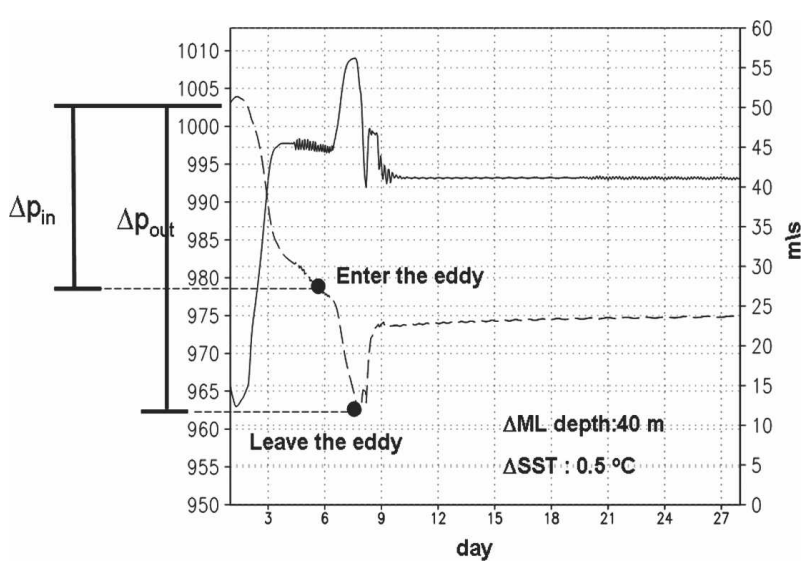

FIG. 13. Time series of the sea level central pressure (dashed line) and the maximum azimuthal wind (solid line) in the experiment that introduces a $700-\mathrm{km}$-wide warm eddy at day 5 . Here $\Delta p_{\text {in }}$ and $\Delta p_{\text {out }}$ indicate the pressure depression in the eye of the storm as it enters and leaves the warm eddy, and $\Delta \mathrm{ML}$ and $\Delta \mathrm{SST}$ account for the differences of the mixed layer depth and SST between the standard ocean and the warm eddy.

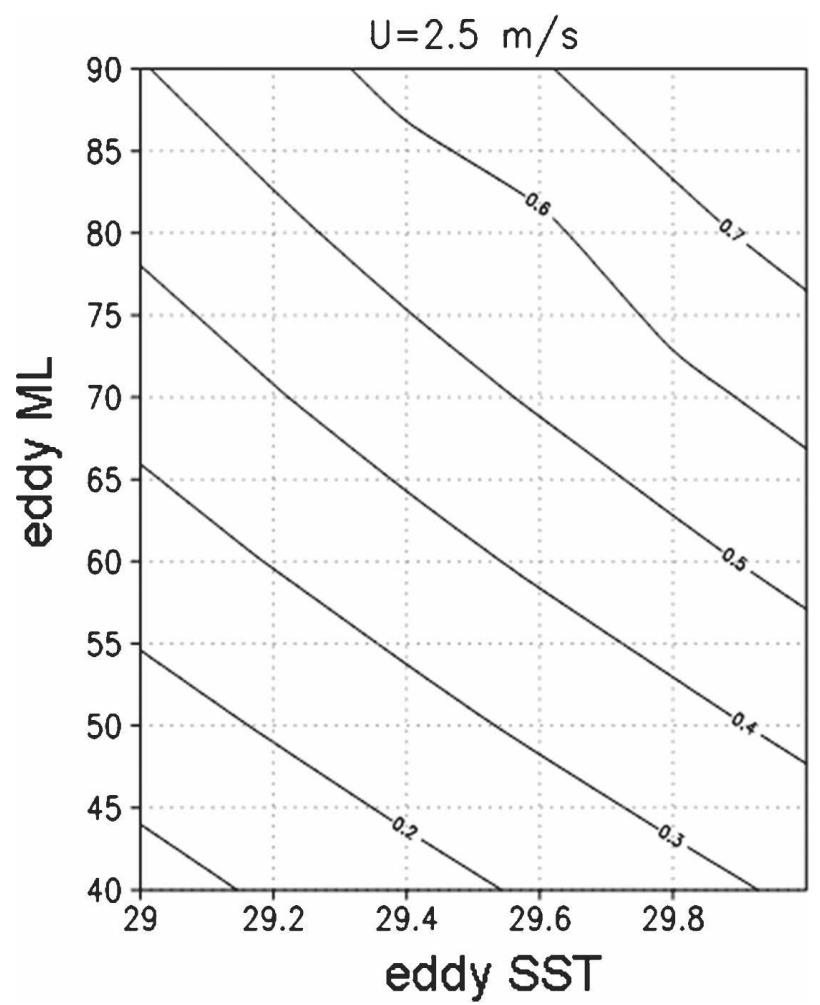

FIG. 14. Same as in Fig. 11, but for $F_{\text {EDDY-T }}$.

function of the SST and the mixed layer depth in the eddy for the case with the storm's translation speed of $2.5 \mathrm{~m} \mathrm{~s}^{-1}$. We also find out that $F_{\text {EDDY-T }}$ increases with both a rising SST and a deepening mixed layer. The relation between $F_{\text {EDDY-T }}$ and the translation speed is also shown in Fig. 12 (dashed line), which displays that $F_{\text {EDDY-T }}$ decreases as the translation speed increases. When the storm moves faster, the time period of TC's encounter with the eddy becomes shorter, and thus the influence of the eddy on the TC intensity becomes weaker than that of a slowly moving storm. The interaction time between the TC and the ocean eddies also depends on both the storms' translation speed and the size of the eddy. Figure 15 shows the $F_{\text {EDDY-T }}$ as a function of the eddy size and the translation speed. In general, $F_{\text {EDDY-T }}$ increases with either the increase of eddy size or the decrease of the storm's translation speed due to the longer interaction time.

\section{3) Comparison of the values of F EDdy-T BETWEEN THE MODEL AND THE REAL-CASE STORMS}

The previous analysis on $F_{\mathrm{EDDY}}$ is performed under the idealized situations using a relative simplified coupled model. It is interesting to know whether such a 


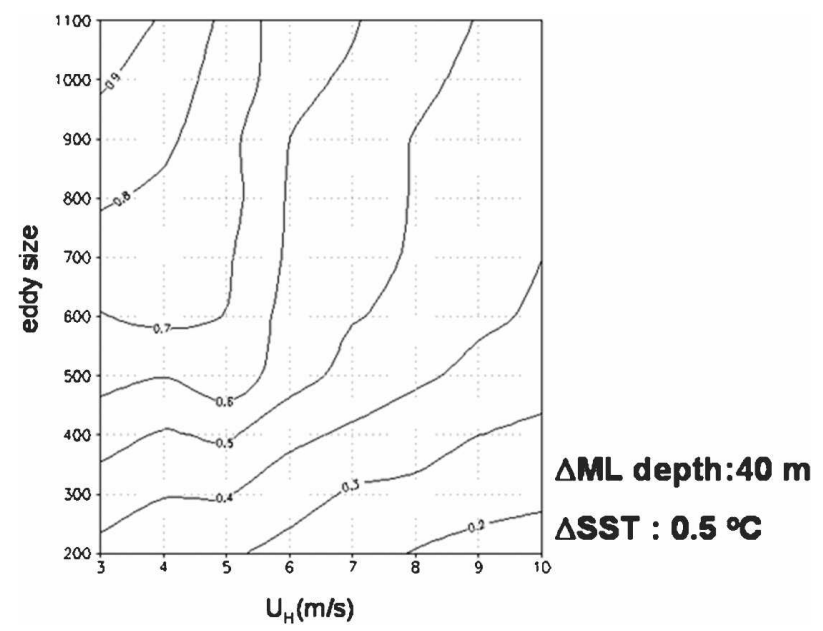

FIG. 15. $F_{\text {EDDY-T }}$ as a function of the eddy size $(\mathrm{km})$ and the TC's translation speed $\left(\mathrm{m} \mathrm{s}^{-1}\right)$. Here $\Delta \mathrm{ML}$ and $\Delta \mathrm{SST}$ account for the differences of the mixed layer depth and SST between the standard ocean and the warm eddy.

model can reproduce the response of the real TC when it encounters the ocean eddies. The eddy feedback effect for real-case storms can also be quantified by $F_{\text {EDDY-T }}$ with both $\Delta p_{\text {in }}$ and $\Delta p_{\text {out }}$ estimated through observation. We calculate the $F_{\text {EDDY-T }}$ for two real cases: Supertyphoon Maemi (2003) and Hurricane Opal (1995), and then compare the values of $F_{\text {EDDY-T }}$ from these real storms with the values of the $F_{\text {EDDY-T }}$ from our simple coupled model experiments.

By taking the data from the Joint Typhoon Warning Center (JTWC), we find that the initial minimum sea level pressure of Supertyphoon Maemi (2003) was 1004 $\mathrm{hPa}$ when the depression was first identified. Supertyphoon Maemi intensified from 954 to $885 \mathrm{hPa}$ as it passed the warm ocean eddy, and the corresponding $F_{\text {EDDY-T }}$ is therefore 1.38 (Table 2); that is, Maemi's intensity was strengthened by $138 \%$ because of an encounter with the warm ocean eddy. From the assimilated data of NPACNFS, the SST was $28.5^{\circ} \mathrm{C}$ and mixed layer depth in the warm ocean eddy was $75 \mathrm{~m}$ before Maemi's arrival, while those outside the eddy region were $28.25^{\circ} \mathrm{C}$ and $20 \mathrm{~m}$, respectively. Maemi's mean translation speed during this period is about $3.4 \mathrm{~m} \mathrm{~s}^{-1}$ (estimated based on the best track data of the JTWC). By selecting the typical value of the lapse rate of the upper thermocline to be $0.06^{\circ} \mathrm{C} \mathrm{m}^{-1}$ (estimated from the NPACNFS profile), we derive that the corresponding $F_{\text {EDDY-T }}$ of the coupled model is 0.93 (Table 3), which is $33 \%$ smaller than the observed value indicated above.

For the same calculation, we also show that the estimated value of $F_{\text {EDDY-T }}$ for Opal based on the observed sea level pressure information is 1.19 , while the value of
TABLE 2. The values of observed $F_{\text {EDDY-T }}$ for Hurricane Opal (1995) and Supertyphoon Maemi (2003).

\begin{tabular}{|c|c|c|}
\hline Properties & Opal (1995) & Maemi (2003) \\
\hline Basin & Gulf of Mexico & $\begin{array}{l}\text { Western North } \\
\text { Pacific }\end{array}$ \\
\hline Eddy type & Warm core ring & $\begin{array}{l}\text { Warm ocean } \\
\text { eddy }\end{array}$ \\
\hline Tropical depression & $1006 \mathrm{hPa}$ & $1004 \mathrm{hPa}$ \\
\hline $\begin{array}{l}\text { Central pressure } \\
\text { (entering the eddy) }\end{array}$ & $965 \mathrm{hPa}$ & $954 \mathrm{hPa}$ \\
\hline $\begin{array}{l}\text { Central pressure } \\
\text { (exiting the eddy) }\end{array}$ & $919 \mathrm{hPa}$ & $885 \mathrm{hPa}$ \\
\hline $\begin{array}{l}\Delta P \text { (difference of the } \\
\text { above two terms) }\end{array}$ & $46 \mathrm{hPa}$ & $69 \mathrm{hPa}$ \\
\hline Observed $F_{\text {EDDY-T }}$ & 1.19 & 1.38 \\
\hline $\begin{array}{l}\text { Data source of the } \\
\text { best track }\end{array}$ & $\begin{array}{l}\text { National Hurricane } \\
\text { Center }\end{array}$ & JTWC \\
\hline
\end{tabular}

$F_{\text {EDDY-T }}$ from the model is 0.5 . In the cases of both Maemi and Opal, the values of the observed $F_{\text {EDDY-T }}$ are higher than those from the model, possibly because the model tends to underestimate the storm intensity (because of the limited model resolution, despite of the fact that axisymmetric assumption would favor the storm to reach higher intensity) and it does not consider other effects of the atmosphere (such as the impact of the presence of the upper-tropospheric trough in Opal's case). Nevertheless, we believe that the proposed index, $F_{\mathrm{EDDY}-\mathrm{T}}$, can be an effective measure of the eddy's impact on the TC intensity.

\section{4) A general Function FOR $F_{\text {EDDY-T }}$}

Based on previous discussions, $F_{\text {EDDY-T }}$ depends not only on the eddy structure but also on storm's property and atmospheric environment, such as the translation speed and the relative humidity. To find out the functionality of $F_{\text {EDDY-T }}$, some key parameters are chosen, similar to Schade and Emanuel (1999), based on the sensitivity studies in experiment B and the property of the ocean eddies. The SST, unperturbed mixed layer depth (ML), and the stratification below the mixed layer $(\Gamma)$ represent the standard oceanic conditions that affect the magnitude of the ocean's negative feedback. The storm size $(\eta)$ and the translation speed $\left(U_{H}\right)$ determine the interaction time scale between the atmosphere and ocean. Besides, $U_{H}$ also determines the interaction time scale between the TC and the ocean eddy. The environment boundary layer relative humidity $(H)$ is also an important parameter because it affects the steady-state TC intensity and determines the thermodynamic disequilibrium at the sea surface (Schade and Emanuel 1999). Finally, the SST (SST EDDY) and the mixed layer depth $\left(\mathrm{ML}_{\mathrm{EDDY}}\right)$ in the eddy structure are chosen to represent the eddy. To distinguish the 
TABLE 3. The values of modeled $F_{\text {EDDY-T }}$ for Hurricane Opal (1995) and Supertyphoon Maemi (2003).

\begin{tabular}{|c|c|c|}
\hline Properties & Opal (1995) & Maemi (2003) \\
\hline Basin & Gulf of Mexico & $\begin{array}{l}\text { Western North } \\
\text { Pacific }\end{array}$ \\
\hline Large-scale ocean's SST & $29^{\circ} \mathrm{C}$ & $28.25^{\circ} \mathrm{C}$ \\
\hline Large-scale ocean's ML & $40 \mathrm{~m}$ & $20 \mathrm{~m}$ \\
\hline EDDY's ML & $120 \mathrm{~m}$ & $75 \mathrm{~m}$ \\
\hline $\begin{array}{l}\text { Storm's displacement } \\
\text { distance within the } \\
\text { eddy region }\end{array}$ & $316 \mathrm{~km}$ & $522 \mathrm{~km}$ \\
\hline Mean translation speed & $6.2 \mathrm{~m} \mathrm{~s}^{-1}$ & $3.4 \mathrm{~m} \mathrm{~s}^{-1}$ \\
\hline $\begin{array}{l}\text { Central pressure } \\
\text { (entering the eddy) }\end{array}$ & $974 \mathrm{hPa}$ & $989 \mathrm{hPa}$ \\
\hline $\begin{array}{l}\text { Central pressure } \\
\text { (exiting the eddy) }\end{array}$ & $959 \mathrm{hPa}$ & $975 \mathrm{hPa}$ \\
\hline$\Delta P$ & $15 \mathrm{hPa}$ & $14 \mathrm{hPa}$ \\
\hline Model's $F_{\text {EDDY-T }}$ & 0.5 & 0.93 \\
\hline $\begin{array}{l}\text { Data source for the eddy's } \\
\text { thermal structure }\end{array}$ & $\begin{array}{l}\text { Hong et al. } \\
\text { (2000) }\end{array}$ & NPACNFS \\
\hline
\end{tabular}

difference between the SST and $\mathrm{SST}_{\mathrm{EDDY}}, 26^{\circ} \mathrm{C}$ is subtracted from each of the values of SST and $\mathrm{SST}_{\mathrm{EDDY}}$, which is regarded as the reference SST. Table 4 lists the ranges of these eight dimensional parameters.

We first need to suggest the functional form of $F_{\text {EDDY-T }}$ and then use the linear least squares method for the best-fit approximation. Based on the results from the 1944 model experiments, we guess a powerlaw dependence of $F_{\text {EDDY-T }}$ on these parameters of the form

$$
F_{\mathrm{EDDY}-\mathrm{T}}=e^{\lambda_{0}} \prod_{i=1}^{8} D_{i}^{\lambda_{i}}
$$

where $D_{i}$ indicates the $i$ th dimensional parameter and $\lambda_{i}$ is its exponent. Here $F_{\text {EDDY-T }}$ is a nondimensional factor, so the constant in Eq. (18), $e^{\lambda_{0}}$, is a dimensional constant. Equation (18) can be written as a linear form by a logarithmic method:

$$
\ln F_{\mathrm{EDDY}-\mathrm{T}}=\lambda_{0}+\sum_{i=1}^{8} \lambda_{i} \ln D_{i} .
$$

\begin{tabular}{|c|c|c|c|}
\hline & Parameter & Unit & Range \\
\hline$D_{1}$ & $\mathrm{SST}-26^{\circ} \mathrm{C}$ & ${ }^{\circ} \mathrm{C}$ & $2-3$ \\
\hline$D_{2}$ & $\mathrm{SST}_{\mathrm{EDDY}}-26^{\circ} \mathrm{C}$ & ${ }^{\circ} \mathrm{C}$ & $2.2-3.6$ \\
\hline$D_{3}$ & ML & $\mathrm{m}$ & $20-40$ \\
\hline$D_{4}$ & $\mathrm{ML}_{\mathrm{EDDY}}$ & $\mathrm{m}$ & $40-100$ \\
\hline$D_{5}$ & $\eta$ & 1 & $0.6-1.0$ \\
\hline$D_{6}$ & $1-\mathrm{RH}$ & 1 & $75 \%-85 \%$ \\
\hline$D_{7}$ & $\Gamma$ & ${ }^{\circ} \mathrm{C} \mathrm{m}^{-1}$ & $0.04-0.06$ \\
\hline$D_{8}$ & $U_{H}$ & $\mathrm{~m} \mathrm{~s}^{-1}$ & $3-7$ \\
\hline
\end{tabular}

TABLE 4. List of the dimensional parameters.
TABLE 5. Best-fit values of all $\lambda$ 's.

\begin{tabular}{lc}
\hline & Parameter \\
\hline$\lambda_{0}$ & -0.96 \\
$\lambda_{1}$ & -1.88 \\
$\lambda_{2}$ & 2.08 \\
$\lambda_{3}$ & -0.97 \\
$\lambda_{4}$ & 0.98 \\
$\lambda_{5}$ & 0.22 \\
$\lambda_{6}$ & -0.74 \\
$\lambda_{7}$ & 0.45 \\
$\lambda_{8}$ & -0.83 \\
\hline
\end{tabular}

From 1944 numerical experiments and the linear least squares technique, the best-fit function of $F_{\text {EDDY-T }}$ is defined as

$$
\begin{aligned}
F_{\text {EDDY-T }}= & 0.38\left(\mathrm{SST}_{\mathrm{EDDY}}-26^{\circ} \mathrm{C}\right)^{2.08} \\
& \times\left(\mathrm{SST}-26^{\circ} \mathrm{C}\right)^{-1.88}\left(\mathrm{ML}_{\mathrm{EDDY}}\right)^{0.98} \\
& \times(\mathrm{ML})^{-0.97}(\eta)^{0.22} \\
& \times(1-\mathrm{RH})^{-0.74}(\Gamma)^{0.45}\left(U_{H}\right)^{-0.83},
\end{aligned}
$$

and the best-fit value of $\lambda_{i}$ is listed in Table 5. The exponents of Eq. (20) reveal that $F_{\text {EDDY-T }}$ highly depends on the SSTs in both the standard oceanic and eddy's structures. We rewrite Eq. (20) as

$$
\begin{aligned}
F_{\text {EDDY-T }}= & 0.38\left(\frac{\mathrm{SST}_{\mathrm{EDDY}}-26^{\circ} \mathrm{C}}{\mathrm{SST}-26^{\circ} \mathrm{C}}\right)^{1.88} \\
& \times\left(\mathrm{SST}_{\mathrm{EDDY}}-26^{\circ} \mathrm{C}\right)^{0.2}\left(\mathrm{ML}_{\mathrm{EDDY}}\right)^{0.98} \\
& \times(\mathrm{ML})^{-0.97}(\eta)^{0.22} \\
& \times(1-\mathrm{RH})^{-0.74}(\Gamma)^{0.45}\left(U_{H}\right)^{-0.83}
\end{aligned}
$$

In Eq. (21), we combine SST and $\operatorname{SST}_{\text {EDDY }}$ and discover that the ratio of the SSTs in these two oceanic structures affects $F_{\text {EDDY-T }}$ drastically. From observation, the SST in warm eddies typically only differs slightly from that outside the eddy region, therefore the first term in Eq. (21) is very close to 1 and the influence of the first term on $F_{\text {EDDY-T }}$ could be ignored. Except for the first term in Eq. (21), the exponent of other parameters can indicate that the mixed layer depths in both the standard oceanic and eddy's structures are the two most important parameters in determining eddy feedback factor, $F_{\text {EDDY-T }}$, while the translation speed, the ambient relative humidity, and the stratification below the mixed layer are the next three.

Equation (20) shows that in this coupled model a stronger eddy feedback effect occurs under any of the following conditions: 
1) higher eddy's SST;

2) thicker eddy's mixed layer depth;

3) lower unperturbed SST;

4) shallower unperturbed mixed layer depth;

5) stronger thermal stratification below the oceanic mixed layer;

6) larger storm size;

7) higher relative humidity;

8) lower translation speed.

The first four conditions imply that when the difference between the standard oceanic and the eddy's thermal structure is greater, and the eddy feedback effect is more significant. In the fifth, sixth, seventh, and eighth conditions, the ocean's negative feedback is also more prominent (Schade and Emanuel 1999). It is suggested that while the condition is favorable to the TC to induce stronger ocean's negative feedback, the influence of eddies on the TC intensity would be more significant. The sixth and eighth conditions closely correspond to our physical intuition; that is, when the TC encounters the eddy for a shorter time period, the eddy feedback effect is less significant.

Figure 16 shows the scatterplot of the model's $F_{\text {EDDY-T }}$ and the best-fit $F_{\text {EDDY-T }}$. The correlation coefficient of 0.97 shows that Eq. (20) is a very good approximation to the distribution of the eddy feedback factor in our experiments. In other words, Eq. (20) can account for the dependence of the eddy feedback factor on the above eight dimensional parameters in this simple coupled model.

\section{Conclusion and future work}

It is well known that the interaction between the TC and ocean eddies is critical to TC's evolution. Lin et al. (2005) showed that a large percentage of TCs in the northwestern Pacific basin encounter ocean eddies during their lifetime. Therefore, to improve the prediction of the TC intensity, quantification of the eddy's impact on the TC intensity is very critical. This study is aimed at addressing this important issue systematically by a simple ocean coupled model.

First we adopt the assimilated data of Maemi (2003) from NPACNFS to show the corresponding SST cooling and storm intensity due to different underlying oceanic structures in the simple coupled model. We found that the storm's final steady-state intensity and the ocean's negative feedback strongly depend on the upper-oceanic thermal structures in those coupled experiments, while the SST feedback factor [Eq. (15)] nearly correlates with the induced reduction of the SST in the storm center linearly. Results from the sensitivity tests

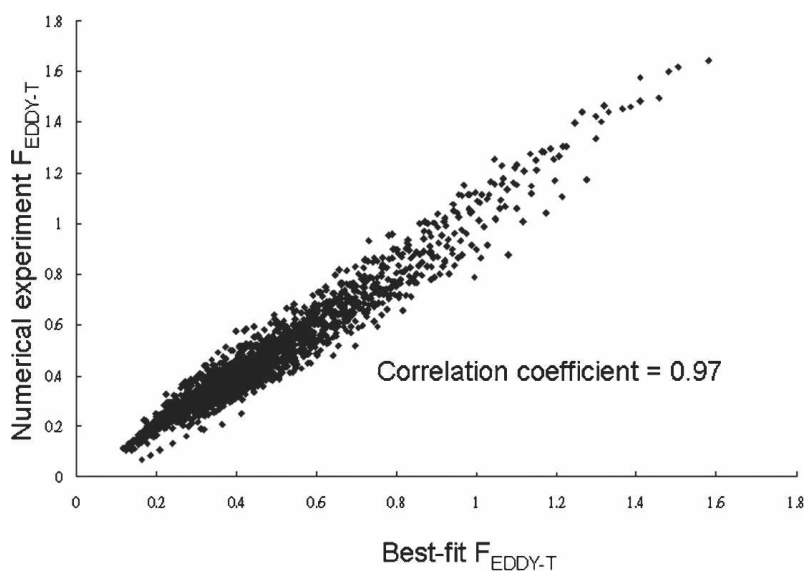

FIG. 16. Scatterplot of the modeled $F_{\text {EDDY-T }}$ and the best-fit $F_{\text {EDDY-T }}$. The correlation coefficient is 0.97 .

of the parameters of the upper-oceanic thermal structure suggest that the steady-state TC intensity is most sensitive to, among the parameters, the mixed layer depth. We also found a linear relation between these four parameters; that is, SST, mixed layer depth, temperature jump and the stratification below the mixed layer, and the SST feedback factor [Eq. (15)].

The eddy experiments are divided into two parts in this study, where we define the eddy feedback factor in each part to quantify the eddy effect on TC intensity.

\section{a. A storm encounters a perpetual eddy}

Results in section $3 \mathrm{c}(1)$ show that the TC intensifies rapidly when encountering the warm ocean eddy in this model, and its final steady-state intensity in the eddy environment does not depend on when the storm encounters the ocean eddy. The eddy's response to the TC depends on two mechanisms. One is that the thicker mixed layer in the warm eddy restricts the induced SST cooling in the storm center, which is consistent with the insulation effect as described in Lin et al. (2005); the other is that higher SST in the warm eddy leads to stronger SST cooling in the trailed right-hand side wake region due to the presence of the stronger TC. The eddy feedback factor, $F_{\text {EDDY-s }}$, increases with the eddy's SST and mixed layer depth, thus indicating that the eddy feedback effect on TC intensity is stronger when the eddy's SST (mixed layer depth) is higher (thicker).

\section{b. A storm passes (transiently) a warm eddy for a finite time}

In the experiments in section $3 c(2)$, the storm is allowed to pass and leave the eddy region. It is found that the storm intensifies transiently while encountering the 
warm eddy, but the storm's intensity reduces quickly as it moves out of that eddy region. The transient eddy feedback factor, $F_{\text {EDDY-T }}$, increases with higher eddy's SST and mixed layer depth.

When TC moves faster or the eddy size is smaller, the interaction time scale between the TC and the warm ocean eddy becomes shorter and thus the $\mathrm{F}_{\text {EDDY-T }}$ is smaller. To know whether such a model can reflect the response of real TCs as they encounter the ocean eddies, we compare the modeled $F_{\text {EDDY-T }}$ with the observed one based on two real cases: Supertyphoon Maemi (2003) and Hurricane Opal (1995). It is shown that the observed $F_{\text {EDDY-T }}$ is higher than the modeled one, possibly because the model tends to underestimate the storm intensity and the model does not consider other effects of the atmospheric environment, such as the upper-tropospheric trough in Opal's case. However, we believe that the proposed index, $F_{\text {EDDY-T }}$, can be an effective measure of the eddy's impact on the TC intensity.

From a simple mathematical method and a set of numerical experiments we also deduce the dependences of $F_{\text {EDDY-T }}$ on a set of governing parameters. It is shown in Eq. (20) that stronger eddy feedback effects exists while (a) the difference of SST and the mixed layer depth between the standard oceanic and eddy's structures is larger, (b) the eddy's mixed layer is deeper, (c) the interaction time scale between the TC and ocean eddy is longer, or (d) the ambient condition is more favorable to a TC to induce stronger SST cooling.

Based on a simple ocean coupled model, in this study we have conducted a useful investigation into the ocean's upper thermal structure, particularly the warm eddy, as a factor affecting the TC intensity. Note that the negative effect of the cold eddies on the TC intensity can also be found based on the same model (not shown here).

In conclusion, this paper has used the simple typhoon-ocean coupled model to assess the effect of the warm ocean eddy on the intensity of typhoons. We believe that this work will aid in improving our basic understanding of the factors influencing TC intensity and perhaps lead to better observation strategies for future forecasts of TC intensify. Note that, however, there are some limitations of this simple coupled model.

The major restriction of this idealized coupled model is the axisymmetric assumption that neglects the impact on typhoon intensity from the asymmetric features including the environmental vertical wind shear and internal dynamics (such as vortex Rossby waves, spiral rainbands, mesoscale vortices, and eyewall processes), as reviewed in Wang and $\mathrm{Wu}$ (2004). Recent work from Yang et al. (2007) showed that the absence of internally generated inner-core asymmetry would result in a stronger simulated typhoon; that is, the internal asymmetry is a limiting factor to the potential intensity. The influence of storm-induced asymmetric SST anomalies, though, is not important and is also ignored under the axisymmetric assumption.

In addition to the axisymmetric assumption in hurricane models, the entrainment parameterization (Price 1981) applied in the ocean model only considers the effect of the vertical shear and ignores two other important factors: wind-driven shear and the convective overturning due to the surface buoyancy fluxes. Ginis (1995) showed the storm-induced SST anomalies calculated by various entrainment parameterizations (his Fig. 5.13). His results revealed that, except for the left side of the track, the magnitude and major pattern of storm-induced SST anomalies based on Price's method are similar to those based on Deardorff (1983), which considers all three mechanisms mentioned above. Thus, we believe that ignoring the influence of wind-driven shear and convective overturning in this study would not adversely affect the results of the numerical experiments.

Nevertheless, use of a more sophisticated atmospheric model to address the above issues is planned. Meanwhile, the current study only focuses on the ocean initiated from a rest condition. In addition to the ocean eddy, the potential impact of the strong ocean currents-such as the strong horizontal heat transport from the Kuroshio or Loop Currents-on the TC intensity would also be a very interesting topic for future investigation.

Acknowledgments. The authors wish to thank Kerry A. Emanuel, Lars R. Schade, and Robert L. Korty for their kind help in providing the coupled model. Thanks also go to Dr. Dong-San Ko for offering the NPACNFS data. Valuable comments from the anonymous reviewers are also appreciated. This work is supported by Grants NSC 93-2111-M-002-003 and NSC 94-2119-M002-006-AP1.

\section{REFERENCES}

Bender, M. A., and I. Ginis, 2000: Real-case simulations of hurricane-ocean interaction using high-resolution coupled model: Effects on hurricane intensity. Mon. Wea. Rev., 128, 917-946.

$\longrightarrow, \ldots$, and Y. Kurihara, 1993: Numerical simulation of tropical cyclone-ocean interaction with a high-resolution coupled model. J. Geophys. Res., 98, 23 245-23 263.

Chan, J. C. L., Y. Duan, and L. K. Shay, 2001: Tropical cyclone intensity change from a simple ocean-atmosphere coupled model. J. Atmos. Sci., 58, 154-172.

Cione, J. J., and E. W. Uhlhorn, 2003: Sea surface temperature 
variability in hurricanes: Implications with respect to intensity change. Mon. Wea. Rev., 131, 1783-1796.

Cooper, C., and J. D. Thompson, 1989: Hurricane-generated currents on the outer continental shelf. Part I: Model formulation and verification. J. Geophys. Res., 94, 12 513-12 539.

Deardorff, J. W., 1983: A multi-limit mixed-layer entrainment formulation. J. Phys. Oceanogr., 13, 988-1002.

Emanuel, K. A., 1989: The finite amplitude nature of tropical cyclogenesis. J. Atmos. Sci., 46, 3431-3456.

- 1999: Thermodynamic control of hurricane intensity. $\mathrm{Na}$ ture, 401, 665-669.

— C. DesAutels, C. Holloway, and R. Korty, 2004: Environmental control of tropical cyclone intensity. J. Atmos. Sci., 61, 843-858.

Fu, L. L., and A. Cazenave, Eds., 2001: Satellite Altimetry and Earth Sciences: A Handbook of Techniques and Applications. Academic Press, 463 pp.

Ginis, I., 1995: Ocean response to tropical cyclones. Global perspectives on tropical cyclones. World Meteorolocial Organization Tech. Doc. 693, 287 pp.

Goni, G. J., and J. A. Trinanes, 2003: Ocean thermal structure monitoring could aid in the intensity forecast of tropical cyclones. Eos, Trans. Amer. Geophys. Union, 84, 573-580.

Hong, X., S. W. Chang, S. Raman, L. K. Shay, and R. Hodur, 2000: The interaction between Hurricane Opal (1995) and a warm core ring in the Gulf of Mexico. Mon. Wea. Rev., 128, 1347-1365.

Kaplan, J., and M. DeMaria, 2003: Large-scale characteristics of rapidly intensifying tropical cyclones in the North Atlantic basin. Wea. Forecasting, 18, 1093-1108.

Ko, D. S., R. H. Preller, G. A. Jacobs, T. Y. Tang, and S. F. Lin, 2003: Transport reversals at Taiwan Strait during October and November 1999. J. Geophys. Res., 108, 3370, doi:10.1029/ 2003JC0011836.

Korty, R. L., 2002: Processes affecting the ocean's feedback on the intensity of a hurricane. Preprints, 25th Conf. on Hurricanes and Tropical Meteorology, San Diego, CA, Amer. Meteor. Soc., 573-574.

Lin, I.-I., C.-C. Wu, K. A. Emanuel, I.-H. Lee, C.-R. Wu, and I.-F. Pum, 2005: The interaction of Supertyphoon Maemi with a warm ocean eddy. Mon. Wea. Rev., 133, 2635-2649.

Pollard, R. T., P. B. Rhines, and R. Thompson, 1973: The deepening of the wind-mixed layer. Geophys. Fluid Dyn., 3, 381404.

Price, J. F., 1981: Upper ocean response to a hurricane. J. Phys. Oceanogr., 11, 153-175.

Qiu, B., 1999: Seasonal eddy field modulation of the North Pacific Subtropical Countercurrent: TOPEX/Poseidon observations and theory. J. Phys. Oceanogr., 29, 1670-1685.

Schade, L. R., 1997: A physical interpretation of SST-feedback. Preprints, 22d Conf. on Hurricanes and Tropical Meteorology, Fort Collins, CO, Amer. Meteor. Soc., 439-440.

, and K. A. Emanuel, 1999: The ocean's effect on the intensity of tropical cyclones: Results from a simple coupled atmosphere-ocean model. J. Atmos. Sci., 56, 642-651.

Scharroo, R., W. H. F. Smith, and J. L. Lillibridge, 2005: Satellite altimetry and the intensification of Hurricane Katrina. Eos, Trans. Amer. Geophys. Union, 86, 366-367.

Shay, L. K., G. I. Goni, and P. G. Black, 2000: Effects of a warm oceanic feature on Hurricane Opal. Mon. Wea. Rev., 128, 1366-1383.

Wang, Y., and C.-C. Wu, 2004: Current understanding of tropical cyclone structure and intensity changes-A review. Meteor. Atmos. Phys., 87, 257-278.

Wu, L., B. Wang, and S. A. Braun, 2005: Impact of air-sea interaction on tropical cyclone track and intensity. Mon. Wea. Rev., 133, 3299-3314.

Yang, B., Y. Wang, and B. Wang, 2007: The effect of internally generated inner-core asymmetries on tropical cyclone potential intensity. J. Atmos. Sci., 64, 1165-1188. 